\title{
The Role of Withholding in the Self-Enforcement of a Value-Added Tax: Evidence from Pakistan
}

DOI:

10.1162/rest_a_00959

\section{Document Version}

Accepted author manuscript

Link to publication record in Manchester Research Explorer

\section{Citation for published version (APA):}

Waseem, M. (2020). The Role of Withholding in the Self-Enforcement of a Value-Added Tax: Evidence from Pakistan. Review of Economics and Statistics, O(0), 1-44. https://doi.org/10.1162/rest_a_00959

\section{Published in:}

Review of Economics and Statistics

\section{Citing this paper}

Please note that where the full-text provided on Manchester Research Explorer is the Author Accepted Manuscript or Proof version this may differ from the final Published version. If citing, it is advised that you check and use the publisher's definitive version.

\section{General rights}

Copyright and moral rights for the publications made accessible in the Research Explorer are retained by the authors and/or other copyright owners and it is a condition of accessing publications that users recognise and abide by the legal requirements associated with these rights.

\section{Takedown policy}

If you believe that this document breaches copyright please refer to the University of Manchester's Takedown Procedures [http://man.ac.uk/04Y6Bo] or contact uml.scholarlycommunications@manchester.ac.uk providing relevant details, so we can investigate your claim.

\section{OPEN ACCESS}




\title{
The Role of Withholding in the Self-Enforcement of a
}

\section{Value-Added Tax: Evidence from Pakistan*}

\author{
Mazhar Waseem
}

April 2020

\begin{abstract}
I leverage the staggered roll out of VAT in Pakistan to document the role of withholding mechanism in the self-enforcement of a VAT. Focusing on firms already in the tax net, I see how their outcomes respond when the tax is extended upward to intermediates used by them. I find that the upward extension of VAT, which triggers the withholding mechanism, causes an immediate and large (more than 40 log-points) surge in sales reported by firms. The evolution of bunching above the zero-liability point and of input costs reported by firms suggest that this large response is indeed driven by the withholding mechanism. I also explore the role of withholding in the extensive margin compliance choices of firms.
\end{abstract}

Keywords: VAT, Tax evasion, Informality

JEL Classification: $\mathrm{H} 25, \mathrm{H} 26, \mathrm{O} 17$

${ }^{*}$ I thank David Agrawal, Miguel Almunia, Michael Best, Anne Brockmeyer, Michael Devereux, Lucie Gadenne, Francois Gerard, Jim Hines, Niels Johannesen, Adnan Khan, Wojciech Kopczuk, Camille Landais, Ben Lockwood, Michael Keen, Tuomas Matikka, Joana Naritomi, Andreas Peichl, Dina Pomeranz, and Joel Slemrod for helpful insights. I also thank the seminar participants at the University of Manchester, the Institute of Fiscal Studies, the University of Copenhagen, the University of Michigan, the University of Kentucky, the National Tax Association, and the World Bank for helpful suggestions and comments. Financial support from the Economic and Social Research Council (ESRC), UK's Future Research Leaders Program is gratefully acknowledged. This paper was earlier circulated with the title "Information, Asymmetric Incentives, Or Withholding? Understanding the Self-Enforcement of ValueAdded Tax". 


\section{Introduction}

Since 1975, the share of value-added tax (VAT) in total government revenue has risen from $9 \%$ to $20 \%$ in the OECD countries, while the share of income tax has fallen from $30 \%$ to $24 \%$ (OECD, 2017). A comparable shift toward VAT has also occurred in emerging economies, where the tax has been replacing revenues from international trade (Baunsgaard \& Keen, 2010; Cagé \& Gadenne, 2018). The VAT has now been adopted by almost every country in the world, its rates are increasing steadily over time, and it has become a leading source of revenue for governments around the world (International Tax Dialogue, 2013). ${ }^{1}$

This expansion of VAT in large part is driven by the belief that the tax is easier to enforce than its alternatives. It is argued that three distinct mechanisms built into a VAT facilitate enforcement. First, in a VAT each inter-firm transaction is recorded at two places, which creates third-party information that the government can use to enforce the tax better (Kopczuk \& Slemrod, 2006; Pomeranz, 2015; Naritomi, 2019). Second, a VAT creates asymmetric incentives between sellers and buyers to cheat (Pomeranz, 2015). Specifically, underreporting by a seller hurts buyers who cannot claim tax credit to the full extent of inputs used by them. Third, a VAT contains a builtin withholding element to it, as the tax paid on intermediates acquired from registered suppliers gets deducted at the upstream stage (Keen, 2008). The deducted tax functions as input tax if the downstream stage is not registered and as withholding tax if it is. In this way, the withholding mechanism protects revenue paid at the upstream stages, making a VAT a particularly suitable tax in environments where the upstream stages are more formal, which usually is the case in developing and emerging economies. The existing empirical literature has focused primarily on the first two mechanisms with relation to the self-enforcement of a VAT. As a result, we have little empirical evidence on the existence or magnitude of the third mechanism, although a theoretical paper arguing its importance, especially in weak enforcement capacity settings, has been quite influential

\footnotetext{
${ }^{1}$ Other than the US and a few oil-rich states, VAT has now been adopted by every country in the world. In the OECD countries, the standard rate of VAT has gone up on average from $11.7 \%$ at its introduction to $18.7 \%$ in 2013 , increasing by more than 60\% (see Table 1 in the International Tax Dialogue, 2013).
} 
(Keen, 2008). This paper fills the gap. It empirically demonstrates the role of withholding in the self-enforcement of a VAT using the staggered roll out of the tax in Pakistan.

Pakistan decided in principle to implement a VAT in its standard, broad-based form in 1990. The political costs of introducing a new levy, however, are large, and perhaps to mitigate these costs the tax was rolled out in phases. In its initial phase lasting till $1996,{ }^{2}$ the VAT was applied to manufacturing firms only. The base was expanded steadily after that, and the tax was extended to all areas of economic activity in the next five years. I exploit this staggered introduction of the tax for my empirical analysis, focusing in particular on the reform in 1999, whereby the VAT was extended upstream to the energy sector. As a result of the reform, PKR 300 billion worth of economic transactions came under the tax net. More important, a major class of inputs of manufacturing firms untaxed up to that point became taxable. The reform, accordingly, creates a particularly compelling source of variation to identify the role of withholding in the self-enforcement of a VAT.

For this purpose, I focus on manufacturers_-firms that were already in the tax net since 1996 — and see how their outcomes respond as the tax gets extended upstream, bringing their inputs into the tax net. In the standard tax compliance model, such upwards extension does not affect the amount of revenue received by the government. It only affects the timing of the tax remitted by firms and their upstream suppliers. I propose a simple model that rationalizes how such withholding may affect both the timing and the amount of tax remitted in weak-enforcement settings. The intuition of the result is straight forward. In weak-enforcement setting, firms underreport their sales to the extent that their output tax liability is just enough to cover the input tax credit claimed on purchases of intermediates. In this setting, when more intermediates of a firm become taxable raising its input tax claim, it absorbs some of the increase by reporting higher sales. Without such a compensating increase in sales, the firm would fall into the negative tax liability region, where the costs of evasion are discretely higher.

To estimate the impacts of the 1999 policy change, I employ a simple difference-in-differences

${ }^{2}$ Pakistan's financial year begins from July. Any reference to year $t$ in this paper refers to the financial year from July $t$ to June $t+1$. 
methodology, comparing the outcomes across manufacturers and importers. Importers are a natural control group in this setting. Using input-output linkages data, I show that they are almost unexposed to the 1999 reform. The key identification assumption here is that absent the policy change the outcomes of both manufacturers and importers would have evolved similarly. Using a long panel of tax records, I show that this assumption is indeed highly plausible in my setting. Employing both event study and regression-based framework, I document that the upstream extension causes an immediate, statistically significant, and economically large (40 log-points) rise in sales reported by manufacturers. This finding is remarkably robust to alternative specifications, including allowing each industry and region to have its own time trend.

I present two further pieces of evidence to substantiate the role of withholding in the response documented above. First, I show that consistent with the proposed framework, there is a strong bunching of firms just above the zero-liability point. Since the zero-liability point has no relevance to the production function of the firm or the market environment it operates in, the bunching cannot be explained by factors such as perfect competition (zero profits), liquidity constraints, or any feature of the technology. It can only be explained by a discontinuous rise in evasion costs at the zero-liability point arising from audit rules, whereby the tax authority audits firms reporting negative liability more frequently. Comparing the bunching across 1998 and 1999, the years before and after the energy sector became taxable, I show that consistent with the proposed framework firms absorb some of the increase in their input tax, reporting higher sales and thereby reducing the amount they evade. Second, I show that reported sales of manufacturers go up by nearly the same amount their taxable input costs go up by, illustrating that the rise in sales is to cover up the rise in input tax resulting from the statutory extension of VAT to more inputs.

I also explore the role of the withholding in the extensive margin choices of firms. I show that extending VAT to more inputs of manufacturers accelerates their entry into the formal regime. Such formalization occurs in two stages. In the first stage firms register and in the second they begin filing. I find that the 1999 reform accelerates the registration of manufacturers. These firms begin filing a few periods later, with firms facing higher formalization incentive (lower value- 
addition) on average doing so earlier than the others. However, some newly registered firms, in particular those with lower formalization incentive, do not begin filing until the government takes more direct enforcement measures such as inspectors' visit to the business premises. The behavior suggests a complementarity between self-enforcement mechanisms built into a VAT and traditional enforcement.

This paper contributes to a small but growing literature that uses microdata to estimate the enforcement properties of VAT in low-tax-capacity settings (see for example de Paula \& Scheinkman, 2010; Pomeranz, 2015; Carrillo et al., 2017; Naritomi, 2019; Fan et al., 2018). I add to this litera-

ture by documenting the role of withholding in the enforcement of a VAT along both intensive and extensive margins. This upstream channel of compliance, to my knowledge, has not been studied in any of the existing works. On a broader level, I contribute to a rich empirical literature that studies how enforcement technologies, both traditional and nontraditional, impact reporting and participation choices of economic agents, especially in low- and middle-income countries (see for example Bachas \& Soto, 2019; Brockmeyer \& Hernandez, 2017; Waseem, 2019a, 2018; Slemrod et al., 2019).

\section{Conceptual Framework}

One distinguishing feature of VAT relative to its alternatives is that it embeds a withholding mechanism into it. Keen (2008) derives a series of theoretical results showing that the mechanism, to some extent, is the sole reason moving to a VAT, in particular in an economy with significant informality, may improve both revenue and welfare. The central focus of this paper is to test empirically how important this mechanism is to the enforcement properties of a VAT. In a first-best world, withholding is neutral to a firm's compliance choice: it affects the timing of tax remitted but not its amount. This section develops a simple framework showing how in the second-best settings withholding may also impact the amount of tax remitted.

Consider a firm that uses taxable inputs costing $c\left(s_{i}\right)$ and nontaxable inputs costing $\psi\left(s_{i}\right)$ to 
produce $s_{i}$ units of sales. The firm reports taxable sales $\hat{s}_{i}$ and taxable input costs $\hat{c}_{i}$ to the government, remitting the VAT of $T_{i}=\tau\left(\hat{s}_{i}-\hat{c}_{i}\right)$, where $\tau$ is the tax rate. The government does not observe real sales or costs of the firm so that it can underreport sales $\hat{s}_{i}<s_{i}$ or overreport costs $\hat{c}_{i}>c_{i}$ on paying a resource cost of $g\left(s_{i}-\hat{s}_{i}, \hat{c}_{i}-c_{i}\right)$. I make two assumptions on the costs of evasion faced by the firm. First, I make the standard assumption that $g($.$) is increasing and convex$ in the amount of evasion (see for example Slemrod \& Yitzhaki, 2002). Second, I assume that the function $g($.$) features a discrete jump at the point the tax liability becomes negative. This assump-$ tion is motivated by the observation that negative tax liability is a rare occurrence for nonexporting firms, and therefore reporting negative liability frequently may put a firm into the tax authority's radar. I show later that this assumption is reasonable given that there is strong bunching of firms just above the zero-liability point.

Now consider that a hitherto untaxed, major input used by the firm becomes taxable from time $t^{\prime}$. Figures I illustrates the change in behavior induced by this reform in two alternative settings. In the first setting (top two panels), the costs of evasion faced by the firm are large, whereas they are smaller in the second setting (bottom two panels). Note that the analysis is based on minimal assumptions. I assume only that the firm's production and reporting decisions are separable and that it is a profit maximizer, choosing its reports trading off the benefits and costs of evasion. Appendix A.2 presents a formal model that makes these assumptions explicit, providing greater details on the mechanism explained here.

In the top two panels, the reform does not affect the amount of tax received by the government. The tax charged on the hitherto untaxed input is now remitted by the firm's seller. As a result, the input tax adjusted by the firm increases and the VAT remitted by it decreases, but the overall VAT remitted by both the firm and its upstream seller remains the same. This is the standard first-best result that in the no-evasion setting withholding affects the timing but not the amount of revenue received by the government.

In the bottom two panels, the costs of evasion faced by the firm are low. It, accordingly, underreports its sales significantly, reporting just enough to cover the input tax credit. By doing so, 
it avoids falling into the negative-liability region, where the costs of evasion are discretely higher. When the untaxed input becomes taxable, the firm faces the choice of whether to keep reporting the prereform level of sales, which would take it to the negative liability region, or to absorb some of the increase in taxable input costs by reporting higher sales. If the jump in evasion costs at the zero-liability point is sufficiently large, the firm may choose the latter, a case shown in Panels C-D of the figure. In this case, the government receives higher revenue from the firm and its upstream seller, illustrating how withholding may acquire a bite in low-evasion-cost setting that it lacks in the first-best.

In my empirical setting, a reform similar to the one considered above occurs in 1999, when energy - a hitherto untaxed and a major input for manufacturing firms (my population of interest)—becomes taxable. The model generates two clear predictions on the behavior induced by this reform. First, reported sales of manufacturing firms would go up as some of them absorb a part of the increase in input tax credit by reporting higher sales. Second, the distribution of tax liability would shift leftwards, but to the extent that the costs of evasion jump at the zero-liability point firms would continue to bunch just above the point. Appendix A. 2 derives these predictions more formally. I take these predictions to the data in section $\mathrm{V}$ of the paper, exploring the role of withholding in the enforcement of a VAT.

In addition to withholding, a VAT may also affect tax compliance through two other channels. First, a VAT generates third-party information as all inter-firm transactions get recorded at two places, creating a paper trail on such transactions (Kopczuk \& Slemrod, 2006; Pomeranz, 2015; Naritomi, 2019). Second, a VAT makes a downstream firm a stakeholder in the tax charged at the upstream stage, creating asymmetric incentives between sellers and buyers to cheat. ${ }^{3}$ In my empirical setting, however, none of these two mechanisms is likely to affect behavior significantly in 1999. More specific, asymmetric-incentives mechanism is unlikely to be present in 1999 because it works upwards only, from a downstream production stage to an upstream production stage. And

\footnotetext{
${ }^{3}$ Please see an earlier version of this paper (Waseem, 2019b) for details on how these two mechanisms may influence the compliance choice of firms.
} 
the information mechanism is unlikely to be present in 1999 as the extension of VAT to the energy sector as I explain later is unlikely to create significant new information flows. The 1999 reform, thus, creates a clean source of variation to identify the role of withholding in the self-enforcement of a VAT.

\section{Contextual Background}

\section{III.A Introduction and Growth of VAT in Pakistan}

Like many other developing countries, Pakistan introduced VAT in the 1990s. At the time, the country was facing a gradual decline in revenues from falling import tariffs, and a broad-based consumption tax was seen as the long-term solution to bridge the gap. The legislation to implement VAT was enacted in July 1990, but to reduce the political costs of introducing a major new levy, its roll out was staggered into phases. Figure II shows this visually. It plots the number of firms who file a VAT return at least once in a given quarter, highlighting three distinct phases in the development of the tax in the country: introduction (1990-1995), expansion (1996-2000), and steady state (2001 onward). In the introductory phase, the new tax was applied to a very narrow base consisting of a few manufacturing industries only. The tax was systematically expanded after that. It was extended to the rest of manufacturers in 1996; to importers in 1997; to distributors, wholesalers, and retailers in 1998; to energy suppliers in 1999; and to service providers in 2000. Each extension was announced in the June of year $t$ to be effective from the beginning of July of that year. Figure III plots the entry of new firms into the VAT regime, disaggregating the analysis by production stage. It shows that the sharp expansion of the tax during 1996-2000 was in large part driven by the statutory changes. ${ }^{4}$ The majority of firms of a given production stage entered

\footnotetext{
${ }^{4}$ One further thing to note from the figure is that relative to the large spikes created by the statutory events, the macro-driven changes in entry are small. This can be seen by focusing at the post-2002 period during which the tax policy and enforcement environment remained stable. Throughout this fairly long period, the entry of new firms continued to be flat, exhibiting no secular trend, and the macro shocks to the process remained minimal.
} 
the VAT net soon after the tax was extended to the stage.

The expansion of the tax also meant that increasingly more firm transactions came under its coverage. Figure IV illustrates this. Starting from a low base, sales and inputs covered by VAT rose steadily, with quarterly taxable sales increasing from PKR 80 billion at the start of 1996 to around 750 billion by the end of $2000 .^{5}$ The increase was particularly sharp in 1999 when the tax was extended to the energy sector, which includes electricity, gas, petroleum and other forms of fuel. I use this sharp and compelling variation to identify the role of withholding in the enforcement of VAT, as I explain below.

It is important to emphasize that the above extensions of VAT were essentially new levies, and it was not the case that the VAT was replacing any other consumption tax. During the period I focus on (1997-2003), only consumption taxes Pakistan had were the VAT and a few excises. More important, there was no turnover tax system running in parallel with the VAT. This scheme meant that whenever an industry was exempt from VAT, it did not pay any other turnover-based tax (please see Martinez-Vazquez, 2006 or World Bank, 2009 for the structure of consumption taxes in Pakistan). Consistent with this scheme, prior to 1999 supplies of energy sector in the country were not subject to any consumption tax (federal or provincial), and hence the imposition of VAT on these from 1999 was essentially a new tax.

\section{III.B Enforcement Survey}

One other important enforcement event that occurs during my sample period and may impact firm compliance is a nationwide enforcement survey that took place in Pakistan during the period 20002002. The objective of the survey was to promote documentation of the national economy, hoping that it would reduce informality, increase the number of taxpayers, and bring in more revenue. In its original design, teams comprising officials of the tax authority and other law enforcement agencies were to visit firms to deliver a questionnaire. The completed questionnaire was to be retrieved back in the second visit, which was to occur two weeks after the first. The questionnaire

\footnotetext{
${ }^{5}$ One US\$ was worth around fifty PKR in 1999.
} 
firms were asked to fill in was essentially a shortened (single-paged) income tax return, asking questions such as income, assets, and liabilities of the firm. The information was to be reconciled with the firm's inventories and data from other sources, and further enforcement action was to be initiated if any major discrepancy was found.

Unsurprisingly, the survey was unpopular and met resistance from firms, in particular from small traders who boycotted it soon after its announcement on May 24, 2000. After a protracted period of strikes, closedowns, and negotiations, the government and traders reached an agreement on August 22, 2000. The agreement softened the survey, removing its most unpopular provision requiring the physical verification of inventories. The revised survey was completed over the next two years.

The survey represents a one-time effort by the government to tighten tax enforcement in the country through traditional measures such as inspectors' visits. ${ }^{6}$ Unfortunately, I do not observe specific outcomes of the survey, in particular which firms were covered by it. But as I note above, the survey was universal in its scope, designed to cover all firms in the country (GOP, 2000). This indeed is substantiated by data from Pakistan's central bank, which show that in its first year (up to July 2001) a total of $1,842,100$ questionnaires were distributed by the survey, of which $85.8 \%$ were retrieved back (SBP, 2001). By comparison, only 40,000 firms were in the VAT net at the time the survey was initiated (see Figure II-A). It is therefore very likely that all VAT-liable firms, being the largest in the country, were covered by the survey. To the extent that all firms in my sample were covered, my difference-in-differences empirical estimates are unaffected by it unless there is a nontrivial interaction between traditional enforcement and the withholding mechanism I study. I come back to this point in section V of the paper.

\footnotetext{
${ }^{6}$ It is important to emphasize that the survey arose out of political compulsions of the country at the time and was not connected in any way with the planned trajectory of VAT in the country. Pakistan had an unanticipated change in government in October 1999, and the survey was one of the measures the new government took to promote compliance in the country.
} 


\section{III.C Tax Design}

During the period covered in this study, the design of VAT in the country remained fairly similar to its standard form. Firms whose supplies were not exempt were required to register with the tax authority. Exemptions were of two types. A small-firm exemption was available to manufacturers and retailers if their annual turnover did not exceed PKR 1 million (2.5 million from 1999 and 5 million from 2004) and 5 million respectively. ${ }^{7}$ Other than this, a generic exemption applied to firms whose supplies fell in the negative list. The negative list, as noted above, largely operated at the production stage level. After the withdrawal of these exemptions in 1996-2000, the list contained only a few items such as unprocessed food. Firms not required to register could do so voluntarily.

While registered, whether voluntarily or otherwise, firms were obliged to charge VAT on their sales and were allowed to adjust the tax paid on their inputs. In case the adjustment exceeded the output tax, they could carry forward or obtain the refund of the balance amount. There were no transaction costs of claiming a carry forward as firms could do so on their own by ticking a cell on the return form. The tax was destination-based: imports into the country were taxed at the standard rate and exports were zero-rated. Any tax charged on inputs used for exports was refunded. Throughout this paper, I focus solely on the domestic taxable sales of firms, abstracting from exports. Figure A.I plots the standard VAT rate in the country. During the period I focus on, it generally remained at $15 \%$ other than two brief episodes during which it was first increased to $18 \%$ and then reduced to $12.5 \%$.

Firms were required to file a return and remit the tax due every month. The filing was based on the principle of self-assessment and there was no preaudit contact between taxpayers and tax collectors. The filed returns were considered final unless selected for audit. The tax administration at the time did not have the capacity to cross-match transactions electronically. Accordingly, the audit selection was largely based on the information received through the return form. One of the

\footnotetext{
${ }^{7}$ The manufacturers and retailers below the exemption threshold were required to pay tax under a simplified scheme. The scheme was introduced in 1996 and was withdrawn in 2004.
} 
more salient cells on the return form was if the tax liability exceeded zero. Negative tax liability is a rare event for taxpayers other than exporters. Going into the red frequently, in particular by a manufacturer, therefore must have been one of the major triggers of audit. In this sense, the country's VAT enforcement regime was fairly similar to that of many other countries (see for example from Ebrill et al., 2001).

\section{Empirical Strategy}

To document the role of withholding in the VAT's enforcement, I restrict attention to manufacturers - the largest group of firms in terms of both output and revenue-and see how their behavior changes in 1999, when a key class of their inputs, untaxed up to that time, becomes taxable. Since manufacturers were already in the tax net in 1999, the policy change represents a quasi-experiment whereby more VAT on inputs of registered firms begins to get withheld at the upstream stage.

The principal econometric challenge in identifying the effects of the reform is to distinguish them from contemporaneous macro shocks. To see this formally, let $i$ index firms and $t$ units of time. Reported taxable sales of a firm $\hat{s}_{i t}$ are a potentially nonlinear function of tax rate $\tau_{t}$, firm characteristics $\boldsymbol{X}_{i t}$, demand and supply shocks $\lambda_{t}$, and government policy $\theta$

$$
\hat{s}_{i t}=f\left(\tau_{t}, \boldsymbol{X}_{i t}, \lambda_{t} ; \theta\right)
$$

Suppose that in period $t^{\prime}$ the government policy changes from $\theta$ to $\theta^{\prime}$. Using the terminology of the Neyman-Rubin-Holland potential outcomes framework, the effect of the policy change can be expressed as $\Delta_{i t^{\prime}}=\hat{s}_{i t^{\prime}}\left(\tau_{t^{\prime}}, \boldsymbol{X}_{i t^{\prime}}, \lambda_{t^{\prime}} ; \theta^{\prime}\right)-\hat{s}_{i t^{\prime}}\left(\tau_{t^{\prime}}, \boldsymbol{X}_{i t^{\prime}}, \lambda_{t^{\prime}} ; \theta\right)$. Because the second term in this expression-counterfactual sales-is not observed, the effect cannot be estimated without making some assumptions. The first assumption I make is the following

Assumption 1: The functional form of reported sales is log-linear, and the effect of the policy is additive in percentage terms. 
Under this assumption, equation (1) can be written in its estimating form as

$$
\log \hat{s}_{i t}=\alpha_{i}+\beta \cdot \mathbb{1}\left(t>t^{\prime}\right)+\tilde{\boldsymbol{X}}_{i t}^{\prime} \gamma+\tilde{\lambda}_{t}+\varepsilon_{i t},
$$

where $\tilde{\boldsymbol{X}}_{i t}$ now contains the time-varying covariates only and $\tilde{\lambda}_{t}$ absorbs the tax rate. The parameter of interest in this equation $\beta$ is not identified, being indistinguishable from the shocks $\tilde{\lambda}_{t}$. To get around this problem, I follow the standard difference-in-differences methodology, comparing the outcome across manufacturers and importers. Importers are a natural control group in this setup. They are much less affected by the extension of VAT to the energy sector in 1999 than manufacturers are. Using transaction-level data, I show below that their upstream exposure to the energy sector is fifteen times lower than that of manufacturers. ${ }^{8}$

Thus, to the extent that the following assumption

Assumption 2: Conditional on controls, the reported taxable sales of manufacturers $i \in M$ and importers $i \in I$ on average follow the same time path as long as the government policy remains unchanged

$$
\mathbb{E}\left[\hat{s}_{i t}\left(\theta \mid \alpha_{i}, \tilde{\boldsymbol{X}}_{i t} ; i \in M\right)\right]=\mathbb{E}\left[\hat{s}_{i t}\left(\theta \mid \alpha_{i}, \tilde{\boldsymbol{X}}_{i t} ; i \in I\right)\right]
$$

is satisfied, $\beta_{3}$ in the following regression captures the causal effects of the policy change on manufacturers

(4) $\log \hat{s}_{i t}=\alpha_{i}+\beta_{1} \cdot \mathbb{1}(i \in M)+\beta_{2} \cdot \mathbb{1}\left(t>t^{\prime}\right)+\beta_{3} \cdot \mathbb{1}(i \in M) \cdot \mathbb{1}\left(t>t^{\prime}\right)+\tilde{\boldsymbol{X}}_{i t}^{\prime} \gamma+\tilde{\lambda}_{t}+\varepsilon_{i t}$.

I offer two pieces of evidence to support the assumption. First, I estimate placebo specifications corresponding to Equation (4), showing that the difference in outcomes between the two groups

\footnotetext{
${ }^{8}$ Note that I do not assume that importers are insulated from the expansion of VAT, but rather that their exposure to the expansion is much less intense relative to manufacturers. In this sense, any relative difference in the two groups' outcomes represents a lower bound on the response of manufacturers.
} 
remains statistically insignificant for a large number of pre- and post-intervention periods during which the policy environment remains stable. Second, I always complement the regression-based results with event study analyses. A typical event study takes the following form

$$
\log \hat{s}_{i t}=\alpha_{i}^{\prime}+\sum_{r=1}^{r=T} \lambda_{r}^{\prime}+\varepsilon_{i t}^{\prime}
$$

The key objects of interest in this equation are the $\lambda_{r}^{\prime}$ 's. These coefficients denote the log-change in outcome in period $r$ relative to the first period $(r=0)$ once the firm fixed effects have been partialled out. I run these regressions separately for the two groups and plot the coefficients over a long time horizon, indicating the times from which the policy changes take effect. These event study charts permit transparent, visual assessment of the identification assumptions underlying equation (4). All specifications I estimate, whether the event study or the difference-in-differences model, allow unrestricted variance-covariance structure over time at the industry level. ${ }^{9}$

\section{IV.A Data}

The data for this project comprise the universe of VAT returns filed in Pakistan. I focus principally on the period 1997-2003 but extend the analysis to other periods for robustness checks. The VAT return consists of three main sections. In the first section, firms report the aggregate value of their sales, breaking it down into three-domestic taxable, domestic exempt, and exports—components. In the second section, the aggregate value of inputs purchased are reported, divided likewise into the three components. In the final section, firms calculate their tax liability, indicating the tax charged on sales, the tax credited on inputs, and the final tax payable. They select one of the two options - carry forward or refund - in case the tax payable is negative. Since July 2008, firms are also required to file an "invoice summary" as a part of the return. The invoice summary contains transaction-wise details of firms' sales and purchases aggregated up to the level of individual sellers

\footnotetext{
${ }^{9}$ Bertrand et al. (2004) show that this technique works well when the number of entities in the panel are large, which is the case in my empirical application.
} 
and buyers. I use this data for the years 2008-2010 to construct forward and backward linkages between firms of various production stages.

Each firm in the VAT net is assigned a unique registration number and is expected to file every tax period (month). The data, therefore, have a panel structure. In addition to the return data, I use information on firm characteristics from the tax register. This information includes the 4digit industry, date of registration, production stage, and geographic location of the firm. The production stage and 4-digit industry together form the 2-tier system the tax administration uses to classify firms. The broader tier_-production stage_classifies firms into seven categories described in detail in the next section. ${ }^{10}$ The second tier classifies firms on the basis of goods or services they supply, using the 4-digit Harmonized Commodity Description and Coding System (HS Code). ${ }^{11}$ This system characterizes the industry within a given production stage a firm operates in. For example, I observe whether a given manufacturer is a supplier of energy.

\section{IV.B Forward and Backward Linkages}

The Pakistani tax code divides firms into seven production stages: import, manufacturing, distribution, wholesale, retail, services, and export. This classification is based on the principal activity firms undertake. These activities are defined in the tax code. ${ }^{12}$ This scheme of classification of firms corresponds roughly to their position in the supply chain. The typical supply chain for the domestic consumption of goods takes the form shown in Figure A.II.

For my empirical strategy to work, it must be that manufacturers are affected much more by the extension of VAT to the energy sector in 1999 than are importers. In other words, it must

\footnotetext{
${ }^{10}$ Firms may undertake more than one of these activities, in which case the data indicate both the principal and secondary activities.

${ }^{11}$ This system is commonly used by customs administrations around the world to classify traded goods and services.

${ }^{12}$ Manufacturing, for example, is defined as "any process in which an article singly or in combination with other articles, materials, components, is either converted into another distinct article or product or is so changed, transformed or reshaped that it becomes capable of being put to use differently". I reproduce the definitions of other activities in Appendix A.1.
} 
be that energy forms a larger proportion of intermediates used by manufacturers than it does for importers. Table I explores this. Using transaction level data for the years 2008-2010, I construct the forward and backward linkages of firms. These linkages are in large part consistent with the typical supply chain shown in Figure A.II. Manufacturers, as expected, consume 10-15 times more energy as input than do importers. It should not be surprising given that importers sell same-state goods, so that the primary usage of energy for them is for ancillary purposes, such as to light and heat the offices.

One other important takeaway from Table I is that more than half of the sales of manufacturers are to other manufacturers. ${ }^{13}$ It is important for my empirical analysis, as these within-stage linkages can amplify the shock coming from other production stages. More importantly, this scheme suggests that the extension of VAT to the energy sector will have a first-order impact on every manufacturer. But the shock will then strengthen as it propagates through multiple firms within the manufacturing stage.

Ideally, I would have liked to use firm-level forward and backward linkages observed at the baseline to construct the first stage of my empirical strategy. Unfortunately, this is not feasible as the transaction level data are not available prior to 2008. But Table I demonstrates that the inputoutput relationships between production stages are remarkably persistent over time: there is little or no variation across the three years, 2008 to 2010. The persistence implies that the evidence in the table is also relevant to the period I focus on (1997-2003), showing that the VAT extension in 1999 indeed creates the first-stage variation needed for my reduced-form equation (4) to deliver the estimates of interest.

\footnotetext{
${ }^{13}$ This again should not be surprising as goods pass through multiple manufacturing stages before turned into the finished product. For example, the supply chain from raw cotton to finished ready-made garment involves at least five manufacturing processes: ginning, spinning, weaving, dying, and stitching.
} 


\section{IV.C Key Outcomes}

My two primary outcomes of interest are the number of firms in the VAT net and taxable sales reported by them. Under the assumption of no one-sided evasion, a rise in taxable sales implies a rise in government revenue. I show this formally in section V.F. Note that I cannot look at VAT revenue or input costs to estimate the effects of the VAT expansion. As VAT expands, these outcomes change due to both mechanical and behavioral reasons. For example, after an upstream extension downstream firms remit less revenue for the pure mechanical reason that their input tax credit goes up. The evolution of reported sales, on the other hand, provides a clean measure of the effect of interest.

Table A.I presents the descriptive statistics of these two outcomes at three points in time, stratifying the sample by production stage. ${ }^{14}$ Between 1997 and 2003, the number of firm-month observations grows by $70 \%$ for manufacturers and $271 \%$ for importer (see the top row of Panel A). The growth largely results from the entry of firms into the VAT regime, although some of it may reflect that filing becomes more regular with time. My baseline specification includes firm fixed effects, which mitigates any selection issues arising from this. To address such concerns even further, I create two other samples that shut down entry and exit. The first of these (Balanced Panel 1) consists of firms who file a return at least once in every quarter included in the sample (Panel B). These firms remain active throughout the sample period, although they may not file in every tax period. The second restricted sample (Balance Panel 2) has a more stringent criterion. It consists of firms who file the return in every tax period included in the sample (Panel C). I always obtain very similar results from the three samples.

\section{Empirical Results}

My primary population of interest in this paper are manufacturing firms. I restrict attention to the period 1997-2003. During this period, four important events occur that could influence the

\footnotetext{
${ }^{14}$ For space considerations, I collapse sectors other than manufacturing and imports into the "other" category.
} 
reporting behavior of manufacturers: (1) VAT extends downstream to distributors, wholesalers, and retailers in July 1998; (2) VAT extends upstream to energy suppliers in July 1999; (3) VAT extends to service providers in July 2000; and (4) the tax survey begins from May 2000. Given that my central focus is to understand the role of withholding in the self-enforcement of VAT, I focus primarily on the second event. Of the four events, it creates the most compelling variation. Figure IV illustrates that the extension of VAT to the energy sector brings nearly PKR 300 billions worth of transactions into the tax net. In terms of size, this shock is around fifteen times larger than ones created by the VAT extensions in 1998 and 2000. The event also creates the cleanest variation. Table I shows that manufacturers have a strong backward exposure to the energy sector, while my control group (importers) are almost unexposed.

I begin by showing that the reported sales of manufacturers rise significantly as a major class of their inputs becomes taxable from July 1999. To substantiate that this response is driven by the withholding mechanism, I present two further pieces of evidence showing how bunching at the zero-liability point and taxable input costs reported by manufacturers evolve around the time of the 1999 reform. I conclude by analyzing the effects of withholding along the extensive margin.

\section{V.A Taxable Sales Response}

Event Study.-Figure V plots the event study results from equation (5). For Panel A, I estimate the equation on the period July-1997 to June-2003, dropping the dummy for July 1997. The regression is run separately for manufacturers and importers, and the coefficients $\lambda_{r}^{\prime}$ 's are plotted. Panel B displays a DD version of the plot, assessing the statistical significance of the relative difference between the two groups in the given month.

I begin the analysis from July 1997. Before that, importers were not required to remit VAT on their sales. The four events of interest mentioned above are demarcated in the diagram by broken vertical lines. It is important to emphasize that sales of firms depicted in this figure remained taxable throughout the sample period (1997-2003). Any change in reported sales would therefore reflect a behavioral response to the four events and not a mechanical change arising, for example, 
from the extension or withdrawal of VAT to an industry.

Four facts stand out from these plots. First, the outcome trends similarly in the two groups during the periods of no policy change. The DD coefficient remains statistically insignificant in all the twelve months_-July 1997 and June 1998_-during which no change to the enforcement environment takes place. Second, the extension of VAT to the downstream stages elicits almost no response. ${ }^{15}$ Third, the outcomes of manufacturers and importers begin to diverge immediately once the energy sector enters the VAT net: the DD coefficient become significant immediately in July 1999 and remains so in later periods. And finally, the two trends diverge even further as the final two events occur, stabilizing only after the survey gets closer to its conclusion in 2002-03.

The key identification assumption in this setting (Assumption 2 in section IV) requires that the outcome trends similarly in the two groups in the absence of a policy change. The figure shows that it is indeed true for the twelve pre-reform months shown in Panels A-B. Twelve months, however, is a relatively short duration and may not be enough to assess the validity of the assumption. Note that I cannot look at the period prior to July 1997 due to reasons outlined above. But given that I have access to a long panel, I can look at the period after 2003, when impacts from the policy changes considered here had already been dissipated. Panels C-D do that. I replicate the top two panels to the period between July 2004 to June 2010. Clearly, importers are a good control group for manufacturers: reported sales of the two groups track each other quite tightly during the 84 months shown in the plots. ${ }^{16}$

Difference-in-Differences Results.-Table II reports the results from estimating equation (4). The outcome variable is the log of domestic taxable sales, and the Post dummy denotes a tax period after June 1999. To see the impact of the VAT expansion to the downstream stages that occurs in 1998, I add an additional interaction term Manuf $\times 1998$ into the model in even-numbered

\footnotetext{
${ }^{15}$ The relative difference between the two groups remains indistinguishable from zero in nine out of the twelve months between July 1998 and June 1999.

${ }^{16}$ Note that a subsample of importers were allowed to file their returns on a quarterly rather than monthly basis for two years included in these plots—July 2006 to June 2008. The spikes around the mean for the importers' series show the effects of this policy.
} 
columns. I show results for the complete and two balanced panel samples separately. Panel B conducts a placebo analysis. The placebo specification is an exact replica of the baseline specification: I estimate equation (4) on the next seven years 2004-2010, defining the period after June 2006 as the Post period.

Unsurprisingly, the results are in line with the event-study results. The coefficient on the interaction term manuf $\times 1998$ is weak and insignificant, demonstrating that bringing the three downstream stages into the VAT net does not elicit significant behavioral response from manufacturers. In contrast, the coefficient on manuf $\times$ post is both strong and significant, capturing on average a larger than $40 \log$ point growth in the sales of manufacturers relative to importers after June 1999. The placebo exercise validates the empirical strategy. In combination with the graphical evidence above, it confirms that absent any policy changes the outcome indeed evolves similarly in the two groups in a large number of pre- and post-intervention periods. Lastly, the results from the three alternative samples are almost identical, putting to rest any concerns from selective entry into or exit from the complete panel sample.

Table III explores the dynamics of the response. I now focus solely on the complete panel sample and partition the manuf $\times$ post dummy into two. The new manuf $\times$ year term captures the additional sales response in the given year. The sales of manufacturers continue to outgrow those of importers until the end of 2003, becoming indistinguishable from them after that. The dynamic analysis shows that the upstream extension of VAT creates around 24 log-point increase in the sales of manufacturers in 1999. To put this magnitude into perspective, note that roughly $15 \%$ of the purchases of manufacturers are from the energy sector (see Table I). With the extension of VAT to the sector, the taxable inputs of manufacturers would roughly rise by this amount for the pure mechanical reason that energy has become taxable. I show later that manufacturer largely absorb this increase in taxable inputs, increasing their reported sales by almost the amount their taxable input costs go up by. The upward extension of VAT would thus cause a nearly $15 \%$ rise in taxable sales reported by manufacturers over time. This first-round rise will trigger a secondround rise in the taxable inputs of manufacturers as around 55\% of their purchases are from other 
manufacturers. In this way, the initial shock will amplify as it propagates back and forth within the manufacturing sector. Reflecting this phenomenon, the taxable sales of manufacturers go up in multiple steps rather than in one go (see Figure V).

The response in year 2000 and later potentially conflates two effects: (1) reaction to the extension of VAT to services, which occurs in July 2000; and (2) continuing reaction to the extension of VAT to the energy sector, especially in interaction with the enforcement survey, which begins from

May 2000. Table I, however, shows that manufacturers and importers have very little exposure to the services sector. We can therefore rule out the influence of the first event in this response (I present more evidence on this in section V.D below). Note further that the enforcement survey, as I noted in section III.B, covers both manufacturers and importers. To the extent, that it effects both groups of firms similarly, the response in year 2000 and later can capture its influence only if there are significant complementarities between the withholding mechanism (activated by the upstream extension of VAT in 1999) and traditional enforcement (tightened by the enforcement survey). I come back to this point after presenting the extensive margin results in the next section.

\section{V.B Bunching at Zero Tax Liability}

The conceptual framework presented in Appendix A.2 predicts that in a weak enforcement setting where withholding has a bite: (1) there would be bunching of firms toward the right side of the zero-liability point, and (2) the bunching would persist even when more intermediates used by firms become taxable. I now test these predictions of the model.

Figure VI illustrates this analysis. I plot the VAT base (the difference between taxable sales and input costs) reported by manufacturers in bins of PKR 5,000, zooming in on the region around zero. I drop observations where reported taxable sales exactly equal taxable input costs as almost all of these relate to inactive firms who report zero in all cells of the return. Panel A of the figure plots the distribution for the tax year 1998, showing sharp bunching of firms just above the zero-liability point: the bin just above zero contains 14 times as many firms as the one just below zero. Note that taxable inputs costs in 1998 do not include energy (which is still not taxable) and labor (which 
is always nontaxable). The variable plotted in the figure (taxable sales minus taxable costs) hence bears no relevance to the real production side of the firm. Its value lies somewhere in between the turnover and profits of the firm. Bunching in its distribution at the point zero therefore cannot be explained by any real phenomenon such as market competition (zero profits), liquidity constraints, or any feature of the production technology. Nor can it be explained by transaction costs, as firms can costlessly carry forward the excess amount of input tax to the next period. Taxable inputs acquired by a firm in a given month do not need to match exactly with the taxable sales made by it in the period. The only plausible explanation of the bunching therefore is that firms tend to remain in the positive-tax-liability region to avoid attracting the attention of the tax authority.

Panels B-D of the figure test the second prediction of the model. In 1999, a major class of inputs of manufacturers becomes taxable. Because of the mechanical increase in taxable input costs, the distribution of the VAT base should shift leftwards, pushing many of the firms just above zero into the negative liability region. And the distribution indeed shifts leftwards: the 1999 distribution is stochastically (first-order) dominated by the 1998 distribution at all points. Yet, extremely few firms fall into the negative-liability region, and the bunching persists-in fact it becomes even sharper. Figure A.III tests the robustness of these findings. It replicates Figure VI, reducing the bin width to just PKR 1000 (US\$ 20 in 1998-99). The results are very comparable.

\section{V.C Taxable Inputs Response}

The story linking the 1999 reform to the rise in the reported sales of manufacturers, as outlined in the model in Appendix A.2, goes as follows. The deductible VAT of manufacturers goes up in 1999 as a major class of their inputs becomes taxable. To avoid falling into the negative-liability region, where evasion costs are discretely higher, some manufacturers absorb the increased deduction instead of passing it on to the tax liability, thereby reporting higher sales. Since in this story it is the rise in VAT-paid inputs that drives the rise in sales, another way to test it is by looking at how taxable inputs reported by manufacturers behave around this time. I have already mentioned in section IV.C that changes in taxable inputs conflate both mechanical and behavioral effects. 
But if the increase in taxable inputs (sum of mechanical and behavioral effect) nearly equals the increase in taxable sales (pure behavioral effect), it will be another evidence that the withholding mechanism underlies the sales response documented above.

Table A.II conducts this analysis. I replicate Table II but use taxable inputs as the outcome variable in place of taxable sales. One difficulty with looking at this response is that firms do not apportion their taxable inputs by how much of those are utilized in making domestic taxable sales (some manufacturers in the sample export part of their output). To get around this problem, I drop firms who report any exports or nontaxable sales in any of the periods included in the sample. ${ }^{17}$ The taxable sales response of firms in this restricted sample is shown in Table A.III. The results are indistinguishable from those in Table II, confirming that the sample restriction does not create any selection concern. The results are also strictly consistent with the story laid out above. The taxable inputs of manufacturers rise substantially relative to importers after 1999. The increase is almost as large as that in taxable sales (see the corresponding Table A.III). Together, the two facts show that the increased withholding of tax at the upstream stage does not reduce, one-for-one, the tax liability of downstream firms. In fact, firms absorb some of the increase by reporting higher sales. Tax evasion reduces and aggregate tax payment increases as a result-the self-enforcement dividend of VAT.

\section{V.D Participation Response}

I now turn to analyzing the role of the withholding mechanism along the extensive margin. Specifically, I look if the 1999 reform that makes more inputs of manufacturing firms taxable and hence squeezes their rents from operating informally pushes informal manufacturers into the formal sector. For this purpose, I compare their entry into the tax net over time with that of importers.

\footnotetext{
${ }^{17}$ Some of the firms classified as manufacturers export the goods produced by them. Throughout this paper, I have focused on domestic taxable sales reported by firms as this variable captures the self-enforcing impact of VAT more cleanly. To be consistent with my earlier analysis, I restrict focus here to taxable inputs utilized in making domestic taxable sales only, dropping manufacturers who report any exports in any of the periods included in the estimation.
} 
Graphical Evidence.-Figure VII presents this analysis. The entry of a firm can be defined to occur at three different points in time: (i) when the firm registers, (ii) when it files its first return, and (iii) when it files its first positive-activity return. ${ }^{18}$ The LHS panels plot the raw data of these three outcomes, while the RHS panels show the corresponding plot in the event study format. The domestic supplies of importers become taxable from July 1997. Due to this, their entry remains noisier than usual in the next few periods, stabilizing only around the end of the tax year (see Figure III-C). I, accordingly, begin the analysis from July 1998.

Importers provide a good counterfactual for manufacturers. For a long period during which the enforcement environment remains stable (2002-05), their outcomes evolve indistinguishably from those of manufacturers. The other striking feature of the plots is that the entry of manufacturers rises sharply in June 2000, jumping roughly eight-fold from an average of around 250 to more than 2,000 (see Panel C). In distinction, the upstream expansion of VAT to the energy sector in 1999 produces a weaker effect: it clearly pushes more manufacturers to register (Panel A) but seems to have little effect on their decision to file a VAT return, positive-activity or otherwise (Panels C and B).

Regression Results. - Table IV formalizes the above analysis. Using importers as a counterfactual, I estimate the fraction of manufacturers pushed into the VAT regime by the enforcement shocks. Columns (4), (7), and (10) report this fraction for the three alternative definitions of entry. I obtain the standard error on the number using a nonparametric bootstrap procedure explained in greater detail below the table. The results show that the expansion of VAT to energy inputs is associated with increased registration of manufacturers (columns 2-4). It is around 58\% higher in 1999 than it would have been in the counterfactual world. This additional registration, however, does not translate into higher filing, which starts picking up from the next year only (columns 5-10). Both registration and filing remain higher than usual in the years 2000 and 2001. Filing, however, outstrips registration in these years, suggesting that some of the firms that begin filing in these

\footnotetext{
${ }^{18}$ I define positive-activity return as a return in which at least one of the cells showing sales or purchases made by the firm during the tax period is nonzero.
} 
years were registered earlier. I investigate this point further below.

The response in the year 2000 and later potentially conflates two effects: (1) a reaction to the extension of VAT to services, which occurs in July 2000; and (2) a continuing reaction to the extension of VAT to the energy sector, especially in interaction with the enforcement survey, which begins from May 2000. Table I, however, shows that manufacturers have little forward or backward linkages with service providers: only around $2 \%$ of their trade is with service providers. It is therefore unlikely that manufacturers' strong participation responses may have arisen from the VAT's extension to services. Figure A.IV explores this point further by zooming in on the period around July 2000. It shows weekly registration of firms between April and December of the year, comparing it across manufacturers, importers, and service providers. Figure A.V replicates the analysis for filing. Since the VAT return is filed every month, this analysis is at a monthly frequency. Both analyses show that the correlation between manufacturers' participation responses and VAT's extension to services is weak: the upsurge in manufacturers' registration and filing in general precedes that of service providers; for example the manufacturers' filing peaks two months earlier than the service providers'. In distinction, both these outcomes, especially filing, exhibit stronger correlation with both the announcement and beginning of the survey. On balance, the evidence therefore suggests that the responses in the year 2000 and later reflect the latter of the two effects mentioned above.

As noted above, the registration response exceeds the filing response in 1999, a trend that reverses the next year. This suggests that some of the firms pushed into registration by the 1999 reform do not begin filing immediately. This is surprising given that the key benefit of registering in 1999 is to claim back the tax withheld at the upstream stage, which can happen only if the firm files its return. Figures A.VI-A.VII probe this finding. Panel A of Figure A.VI, in combination with Figure A.VII, shows that it is common for firms to file their first return a few months after their registration. For example, around 10\% of the manufacturers that filed their first return during 20032005 were registered at least six months earlier. ${ }^{19}$ This ratio, however, is particularly high (more

\footnotetext{
${ }^{19}$ Note that registration could be useful for a firm even without filing. Registered firms can bid on government
} 
than $80 \%$ ) in June 2000, when the enforcement survey gets underway. Panel B of the figure looks at the median value-addition of manufacturers by their first-filing date. Value-addition loosely captures the formalization incentive a firm faces. Higher value-addition, for example, means lower input tax claim and hence lower incentive to formalize. The analysis shows that firms that filed their first return during the survey had significantly higher value-addition and hence lower incentives to formalize.

In sum, the extensive margin story that emerges from the above evidence is that the withholding mechanism of VAT pushes informal firms to formalize. These firms register and begin filing a few periods later, with high-formalization-incentive firms doing so earlier than the others. In the Pakistani context, this formalization process was helped by the direct enforcement measures such as inspectors' visits instituted by the enforcement survey. These direct measures, the evidence shows, are particularly effective in making newly registered firms begin filing, especially the ones that face lower incentive to do so on their own. To this extent, the results suggest a complementarity between self-enforcement mechanisms built into a VAT and physical enforcement.

\section{V.E Robustness}

Given the difference-in-differences research design, the principal identification concern in my setting is that importers may not be a good control group for manufacturers. They, for example, may be more sensitive to external shocks than manufacturers. Although parallel trends for a long series of pre- and post-reform periods as shown in Figure V mitigate this concern, Figure A.VIII addresses it even further. It shows that (1) the USD-PKR exchange rate, (2) imports as a percentage of GDP, and (3) the use of imported inputs by manufacturers relative to importers do not change significantly around the time of the 1999 reform. Together, the evidence rules out the concern that

contracts and can attract registered private sector clients. There has been growing evidence in the literature that the VAT leads to market segmentation, whereby registered firms tend to trade with registered firms and unregistered with the unregistered (de Paula \& Scheinkman, 2010; Gadenne et al., 2019; Gerard et al., 2019). Some lag between registration and filing of a newly formalized firm therefore seems natural, as the firm attempts to switch its trading network toward the registered sector. 
the expansion in the sales of manufacturers relative to importers in 1999 was driven by external factors, for example by the availability of cheap imported inputs. Relatedly, Figure A.VIII-F shows that the energy prices in the country also remained stable during this period. This alleviates the concern that the 1999 VAT extension may have coincided with an energy price reduction, causing an expansion in the sale of manufacturers.

To rule out any contemporaneous macro shock affecting the outcomes of manufacturers and importers differentially in 1999, Figure A.IX conducts subgroup analysis estimating the taxable sales response separately for each industry. I estimate equation (4) restricting the sample to firms of one industry only. Panel A plots the Manuf $\times$ Post coefficient and 95\% confidence interval around it from these regressions, comparing it against the baseline coefficient of 0.48 (see column (1) of Table II). Panel B and C replicates the exercise, showing the Manuf $\times 1998$ and placebo coefficients respectively. ${ }^{20}$ The response is quite homogeneous across industries. The coefficient of interest is positive and significant in all but two instances, and the $95 \%$ confidence interval around it contains the baseline coefficient for all but four industries. In contrast, the Manuf $\times 1998$ and placebo coefficients are almost always trivial and insignificant. To the extent that macro shocks affect different industries differently, homogeneous industry-level response rules out any macrobased explanation of the observed response even further. ${ }^{21}$

Tables A.IV-A.VI conduct two additional sets of robustness checks. I first show that the results in Table II are not driven by large firms. Restricting focus to Balanced Panel 1, I replicate the table dropping firms greater than a given cutoff. I use predetermined firm size, dropping firms on the basis of turnover in 1997-1998 in Table A.IV and 1997 in Table A.V. The results from these

\footnotetext{
${ }^{20}$ The industry classifications used here comes from the 2-digit aggregation scheme of the HS Code. The scheme along with the description of the industries is shown in Table A.X.

${ }^{21}$ Table A.XI explores the characteristics of firms in the four industries-wood products; footwear; arms and ammunition; and furniture, where the response is significantly weaker than the average. Firms in these industries are on average smaller, employ less capital, have lower input to output ratios, and are much less likely to register voluntarily. They are thus the least likely to be affected by the expansion of VAT, in particular to its extension to inputs such as electricity and gas, reinforcing the conclusion that the response represents VAT spillovers.
} 
restricted samples are similar to the baseline results. As I note in section III.C, some firms in my sample operate in more than one production stages. For instance, some manufacturers combine their principal activity of manufacturing with a secondary activity such as distribution or retail. Forces created by the expansion of VAT may not act on these multistage firms the same way they do on single-stage firms. Table A.VI addresses this concern. I replicate Table II after reducing the sample to firms who operate in only one sector-manufacture or import—throughout the sample period 1997-2003. There is no meaningful difference between the two set of results. Finally, Tables A.VII and A.VIII allow firms in each industry and tax office to have a separate time trend. The tables show results from equation (4) after including a full set of industry, tax office, period, industry $\times$ period, and tax office $\times$ period fixed effects. I obtain comparable results from these specifications. $^{22}$

\section{V.F Effect on Government Revenue}

How much additional revenue did the government receive from the expansion of sales reported by manufacturers as documented in Table II? Under the assumption of no one-sided evasion, an expansion in sales reported at a given production stage is a sufficient condition that the government collects more revenue from that and any upstream production stages. To see this formally, consider a simple supply chain composed of two production stages (energy and manufacturing sectors in my empirical application). For simplicity, assume that the upstream production stage supplies all its output to the downstream production stage as an intermediate. The aggregate VAT revenue collected from the supply chain is given by

$$
T=\tau \hat{s}_{1}+\tau\left(\hat{s}_{2}-\hat{c}_{2}\right)
$$

\footnotetext{
${ }^{22}$ The only exception to this is the Balanced Panel 2 specification in Table A.VIII, which produces a significantly lower DD coefficient. The specification includes a full set of period, industry, and industry $\times$ period fixed effects and the lower coefficient likely reflects the smaller sample I get by imposing the restriction of having filed in every tax period included in the sample.
} 
which equals $T=\tau \hat{s}_{2}$ if we rule out one-sided evasion meaning that $\hat{c}_{2}=\hat{s}_{1}$. We can safely rule out one-sided evasion in the Pakistani setting as the upstream stage comprises large, publiclyowned firms, whose tax records are always accessible to the government. ${ }^{23}$ Note that the government was not receiving any consumption tax from the energy sector prior to the extension of VAT to the sector in 1999. The rise in sales documented in Table II would therefore result in a rise in VAT revenue of comparable magnitude $\left(\Delta T=\tau \cdot \Delta \hat{s}_{2}\right)$. As I mention in section IV.C, I cannot look at the firm-level VAT revenue directly as an outcome variable because doing so would largely capture the mechanical and not the behavioral effect of VAT expansion. In this section, I look at the aggregate VAT collected in Pakistan to get some sense of the additional revenue generated by the extension of VAT to the energy sector.

Table A.IX conducts this analysis. The FBR reports commodity-wise non-import VAT collected in the country in its annual reports. These reports are publicly available, and I access the 2001-02 to 2004-05 reports to construct this table. ${ }^{24}$ Columns (2) and (3) of the table show that the VAT revenue grew sharply between 1999 and 2002, in particular in $1999 .^{25}$ Some of this growth results from the mechanical expansion of the base, the rest from the behavioral responses. To provide a clean lower-bound on the behavioral component of the growth, columns (4)-(5) exclude the revenue remitted by the energy sector. The commodities included in these columns remain taxable

\footnotetext{
${ }^{23}$ One-sided evasion in this setup means that manufacturers forge their electricity and gas bills to over-claim VAT paid on these inputs i.e. $\hat{c}_{2}>\hat{s}_{1}$. This is highly unlikely as (1) forgery is treated as tax fraud entailing prosecution and (2) electricity and gas bills can easily be verified at the time of audit because they are supplied solely by publicly-owned firms.

${ }^{24}$ The standard VAT rate changed during this period for two brief episodes (see Figure A.I). To make the revenue comparable across years, I normalize it to a rate of $15 \%$ throughout the sample period.

${ }^{25}$ Note that the revenue reported here is the revenue received from all production stages of the domestic supply chain, including the non-manufacturing stages of distribution, wholesale, and retail. But given that (1) the size of the non-manufacturing sectors is an order of magnitude smaller than that of manufacturing (please see Figure IV); and (2) the VAT regime does not change for the distributors, wholesalers, and retailers after 1998, the post-1998 rise in revenue (excluding that from the energy sector) largely capture the additional revenue the government obtains from the manufacturing stage.
} 
throughout the sample period, meaning that any growth in revenue would necessarily reflect the behavioral effect. The numbers provide a lower bound because they do not take into account the VAT deducted by manufacturers on their energy inputs. Columns (6) and (7) take into account these deductions. Using data from the Pakistan Economic Survey, I compute the proportion of energy used as an intermediate good by manufacturing firms. ${ }^{26}$ I then add that proportion of revenue remitted by the energy sector to compute the aggregate revenue.

It is important to emphasize that these time-series aggregates are not directly comparable to the results in Table II: they do not control for macro factors and may be more sensitive to the performance of large firms (the results in Table II include firm fixed effects). Despite these caveats, the aggregate revenue growth is generally in line with the firm-level sales growth documented in Table II. VAT revenues were almost stagnant but grew sharply from 1999 as the energy sector came into the tax net. The results thus confirm that the government received a significantly higher revenue as a result of the withholding mechanism of VAT: the already-taxed sector remitted more revenue as more of their inputs became subject to the tax (see columns 6-7 of the table, which are conceptually closest to the estimates in Table II).

\section{Conclusion}

Value-added tax has seen unparalleled growth in the past few decades. The growth in part has been driven by the belief-held by both public finance academics and policy practitioners — that the VAT facilitates enforcement. This paper leverages the staggered introduction of VAT in Pakistan to document the role of one of the key self-enforcement mechanisms—withholding —in the compliance choices of firms.

For this purpose, I focus on firms already in the tax net and see how their outcomes respond when the VAT is extended upward to intermediates used by them. I find that the upward extension

\footnotetext{
${ }^{26}$ Specifically, I use Table 14 of the Pakistan Economic Survey 2005-06 to compute this proportion for the years 1997 to 2004 . The survey shows that on average around $33 \%$ of electricity, $66 \%$ of gas, and $70 \%$ of other petroleum products (including furnace oil) are used as input by manufacturing firms. The survey can be accessed here.
} 
of the tax causes an immediate, statistically significant, and economically meaningful (40 logpoint) rise in the sales reported by firms. I present two further pieces of evidence to show that this sales response is driven by the withholding mechanism. First, I compare bunching of firms just above the zero-liability point across 1998 and 1999, the year before and after the upward extension, to show that firms make a compensatory increase in their reported sales as more VAT begins to get charged on their inputs. Second, I show that the rise in reported sales is merely enough to cover up the increase in input tax of firms. Together, these three findings are consistent with a model where firms face quite low evasion costs as long as they are in the positive-VAT-liability region. The costs of evasion jump discretely as firms fall into the negative-VAT-liability region. Withholding, in this setting, acquires a bite it lacks in the standard setting, making the VAT a better tax relative to its alternatives, such as a retail sales tax, as the revenue remitted at the upstream stages gets protected.

\section{References}

Bachas, Pierre, \& Soto, Mauricio. 2019. Not (ch) your average tax system: corporate taxation under weak enforcement. World Bank Policy Research Working Paper.

Baunsgaard, Thomas, \& Keen, Michael. 2010. Tax revenue and (or?) trade liberalization. Journal of Public Economics, 94(9), 563-577.

Bertrand, Marianne, Duflo, Esther, \& Mullainathan, Sendhil. 2004. How much should we trust differences-in-differences estimates? The Quarterly journal of economics, 119(1), 249-275.

Brockmeyer, Anne, \& Hernandez, Marco. 2017. Taxation, Information and Withholding: Evidence from Costa Rica. Working Paper.

CAGÉ, Julia, \& GAdenne, LuCiE. 2018. Tax revenues and the fiscal cost of trade liberalization, 1792-2006. Explorations in Economic History, 70, 1-24. 
Carrillo, Paul, Pomeranz, Dina, \& Singhal, Monica. 2017. Dodging the Taxman: Firm Misreporting and Limits to Tax Enforcement. American Economic Journal: Applied Economics, 9(2), 144-64.

de Paula, Aureo, \& Scheinkman, Jose A. 2010. Value-Added Taxes, Chain Effects, and Informality. American Economic Journal: Macroeconomics, 2(4), 195-221.

Ebrill, Liam P, Keen, Michael, Bodin, Jean-Paul, Summers, Victoria P, et al. 2001. The modern VAT. International Monetary Fund.

Fan, Haichao, LiU, Yu, Qian, NAncy, \& Wen, JaYA. 2018. The Dynamic Effects of Computerized VAT Invoices on Chinese Manufacturing Firms. NBER Working Paper.

Gadenne, Lucie, Nandi, Tushar K., \& Rathelot, Roland. 2019. Taxation and Supplier Networks: Evidence from India. Mimeo.

Gerard, François, Naritomi, Joana, Seibold, Arthur, \& Zulian, Bruno. 2019. Two-Tier Tax Systems and Firms: Evidence from Brazil.

GOP. 2000. The Survey for Documentation of National Economy Ordinance, Ordinance No. XV of 2000. Tech. rept. Government of Pakistan. https://tinyurl.com/syt5b75.

International TAx Dialogue. 2013. International Tax Dialogue, Key Issues and Debates in VAT, SME Taxation and the Tax Treatment of the Financial Sector. International Tax Dialogue.

KeEn, Michael. 2008. VAT, Tariffs, and Withholding: Border Taxes and Informality in Developing Countries. Journal of Public Economics, 92, 1892-1906.

Kopczuk, Wojciech, \& Slemrod, Joel. 2006. Putting Firms into Optimal Tax Theory. American Economic Review Papers and Proceedings, 96(2), 130-134.

Martinez-VAzQuez, Jorge. 2006. Pakistan: A Preliminary Assessment of the Federal Tax System. Tech. rept. International Center for Public Policy, Andrew Young School of Policy Studies, Georgia State University. 
NARITOMi, JoAnA. 2019. Consumers as tax auditors. American Economic Review, 109(9), 303172.

OECD. 2017. Revenue Statistics, Organization for Economic Cooperation and Development. URL, https://goo.gl/WC1M1L.

PomeranZ, DinA. 2015. No Taxation without Information: Deterrence and Self-Enforcement in the Value Added Tax. American Economic Review, 105(8), 2539-2569.

SBP. 2001. Annual Report 2000-2001. Tech. rept. State Bank of Pakistan. https://tinyurl.com/wm997hm.

Slemrod, Joel, \& Yitzhaki, Shlomo. 2002. Tax Avoidance, Evasion, and Administration. Chap. 22, pages 1423-1470 of: Auerbach, A. J., \& Feldstein, M. (eds), Handbook of Public Economics, vol. 3. Elsevier.

Slemrod, Joel, Rehman, Obeid Ur, \& Waseem, Mazhar. 2019. Pecuniary and nonpecuniary motivations for tax compliance: Evidence from Pakistan.

Waseem, Mazhar. 2018. Taxes, Informality and Income Shifting: Evidence from a Recent Pakistani Tax Reform. Journal of Public Economics, 157, 41-77.

Waseem, Mazhar. 2019a. Does Cutting the Tax Rate to Zero Induce Behavior Different from Other Tax Cuts? Evidence from Pakistan. Working Paper, University of Manchester.

WASEem, MAZHAR. 2019b. Information, Asymmetric Incentives, or Withholding: Understanding the Self-Enforcment of Value-added Tax. Working Paper, University of Manchester.

World Bank. 2009. Pakistan Tax Policy Report:Tapping Tax Bases for Development. Tech. rept. World Bank. 


\section{FIGURE I: WITHHOLdING AND FIRM BEHAVIOR}
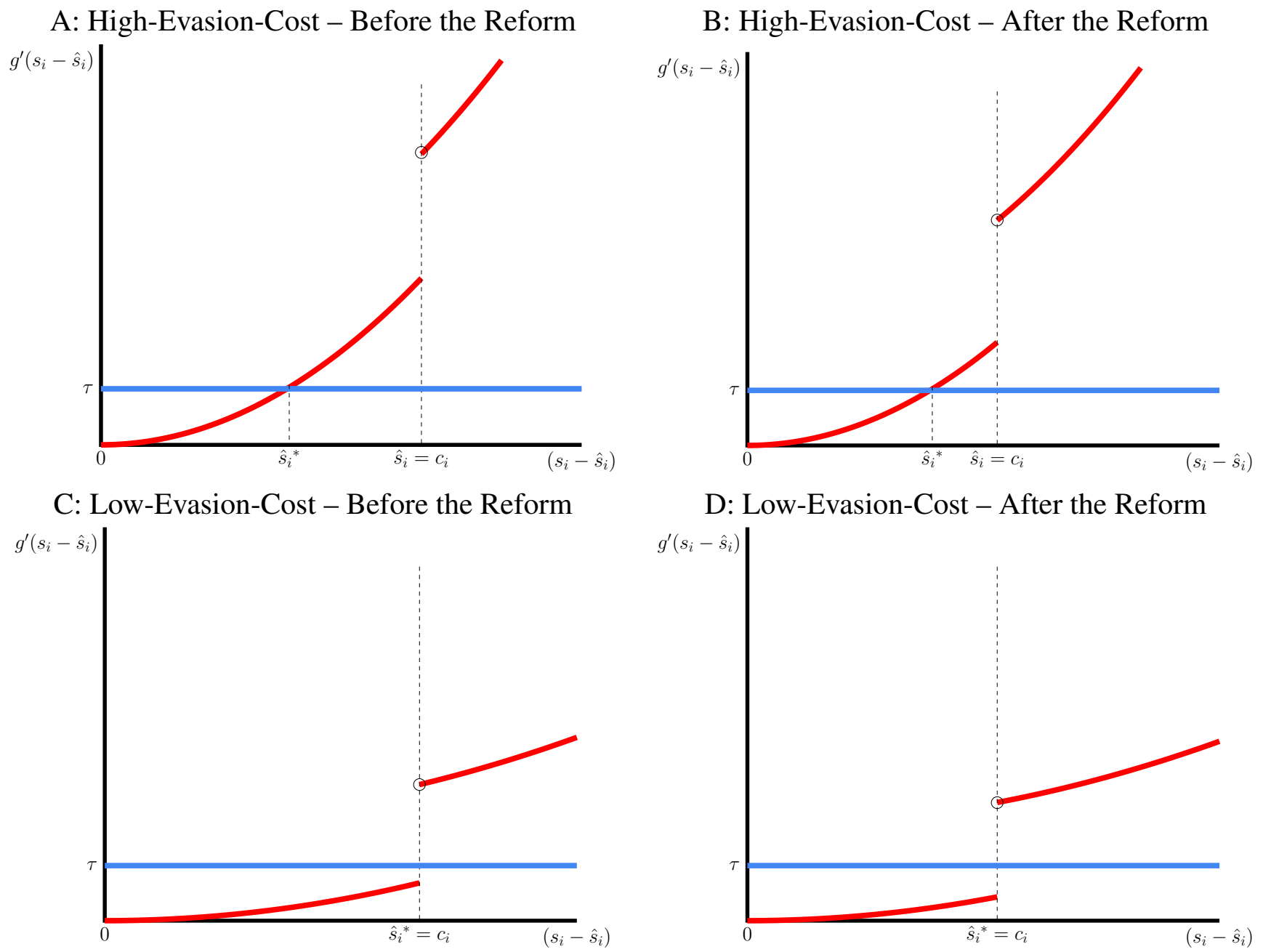

Notes: What happens when more inputs of a firm become taxable? This figure explores the behavior of a firm to such a reform under both high-evasion-cost and low-evasion-cost settings. The plots show marginal evasion costs faced by the firm as a function of the amount evaded. At the origin, reported sales equal true sales and the evasion is zero. Evasion increases as we move toward the right. At the point denoted by the long dashed vertical line, reported sales equal taxable inputs costs of the firm, and as a consequence its tax liability becomes zero. Marginal evasion costs jump at the point, as the tax administration is more likely to select firms who report negative liability for audit. When more inputs of the firm become taxable, the zero-liability point shifts to the left (long dashed vertical line in Panels B and D). Note that the change has no effect on the firm in Panel B as its optimal sales choice was already to the left of the new zero-liability point. But the taxable liability reported by the firms $\tau\left(\hat{s}_{i}-c_{i}\right)$ will shrink as $c_{i}$ is higher now. In Panel $\mathrm{D}$, however, after the reform, the firm increases its reported sales such that the new $\hat{s}_{i}^{*}$ equals the increased $c_{i}$. The increase in reported sales means that the government collects more revenue in aggregate (input plus output) from the firm and its upstream suppliers. 


\section{Figure II: Development of VAT in Pakistan - Number of Firms}

A: All Firms

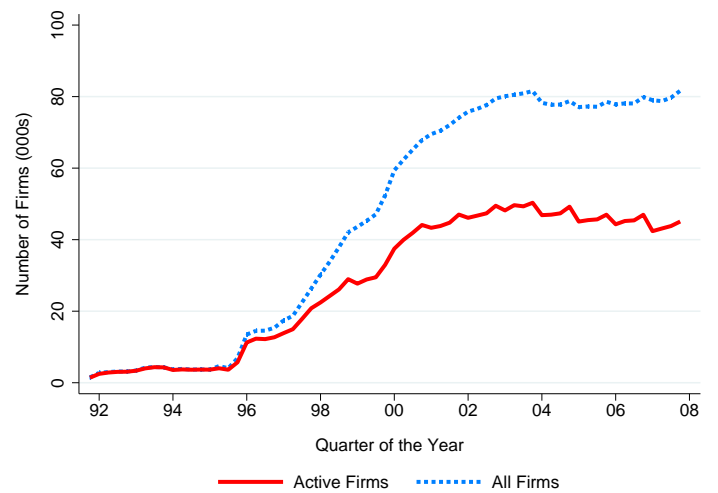

C: Importers

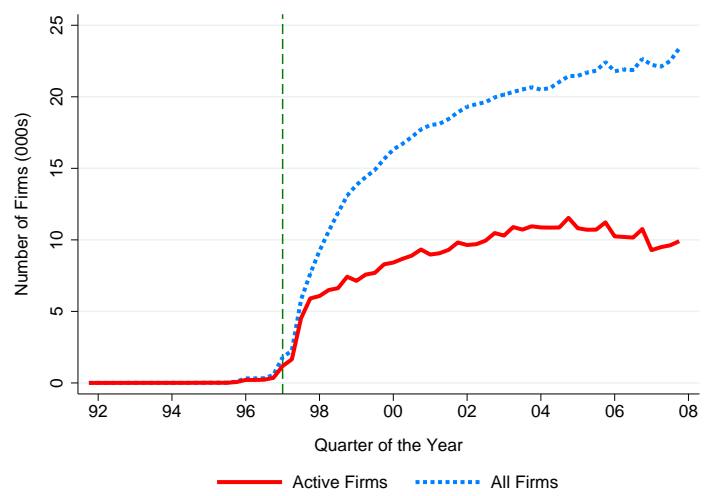

E: Energy Sector

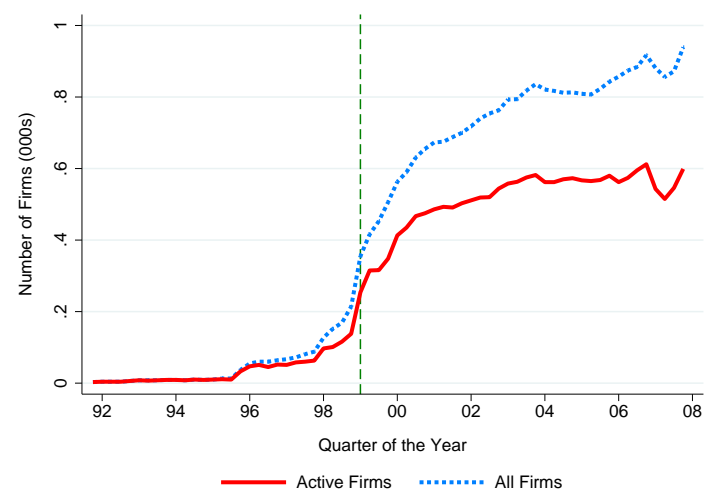

B: Manufacturers

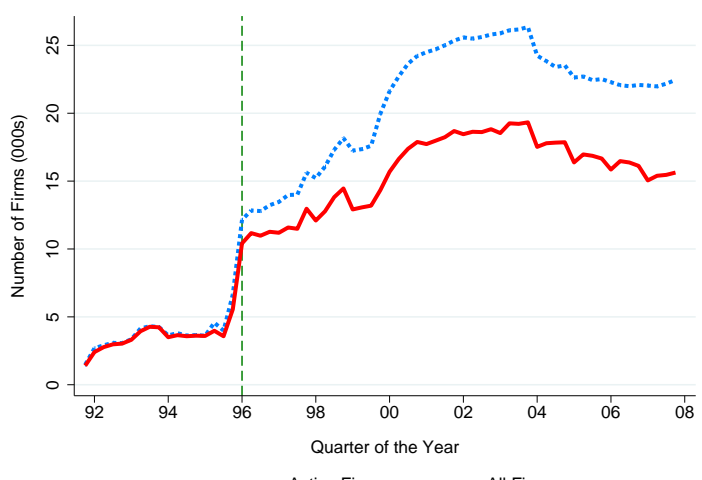

D: Distributors, Wholesalers \& Retailers

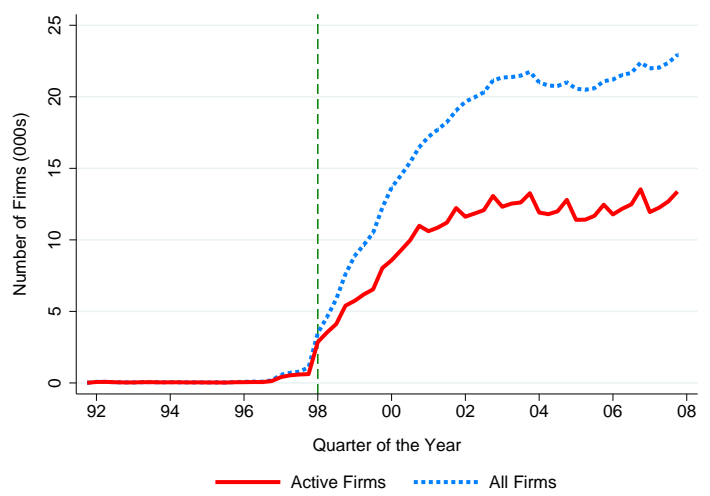

F: Service Providers

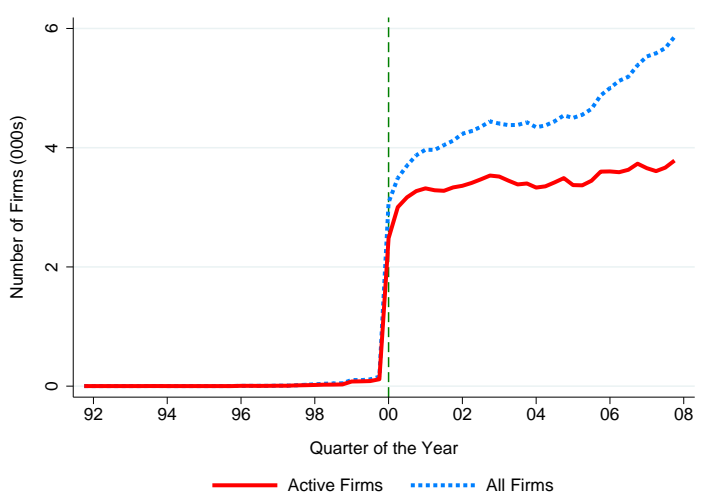

Notes: The figure illustrates the introduction and growth of VAT in Pakistan by tracking the stock of firms in the tax net between 1992 and 2008. It plots the number of firms who file their monthly VAT return at least once in the quarter indicated on the horizontal axis. Year $t$ on the horizontal axis denotes the beginning of the financial year and therefore indicates the July-September quarter. Active firm is defined as a firm who reports nonzero activity in at least one of the cells in the return. Vertical dashed line in each panel demarcate the exact time from which supplies of the production stage became subject to VAT. Please see Appendix A.1 for the classification of firms into manufacturers and other categories. 


\section{Figure III: Development of VAT in Pakistan - Entry of NeW Firms}

A: All Firms

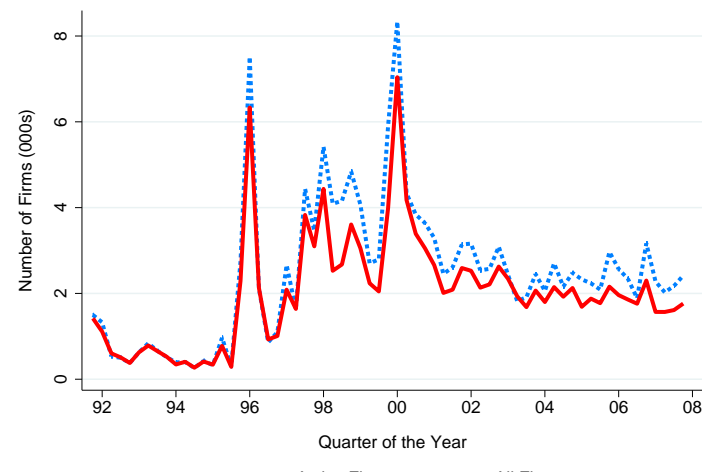

C: Importers

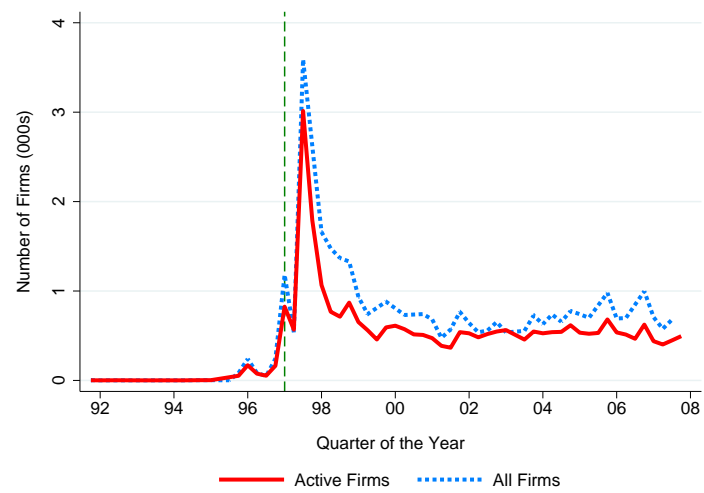

E: Energy Sector

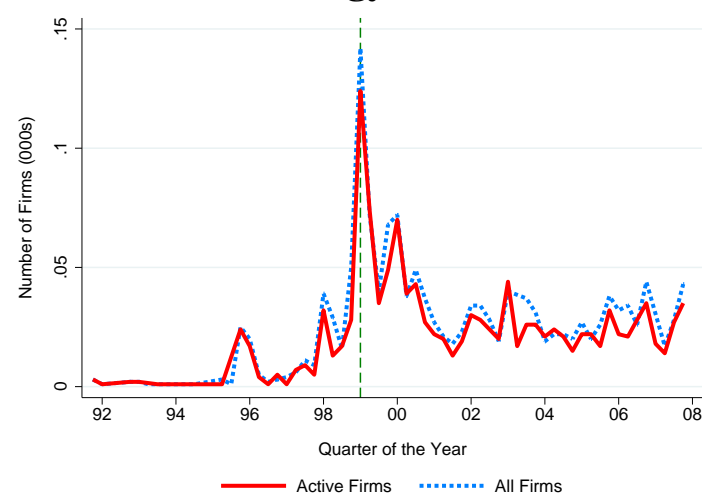

B: Manufacturers

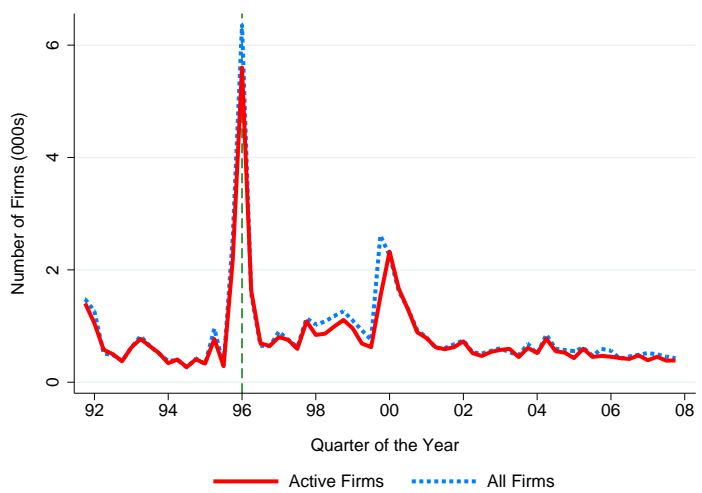

D: Distributors, Wholesalers \& Retailers

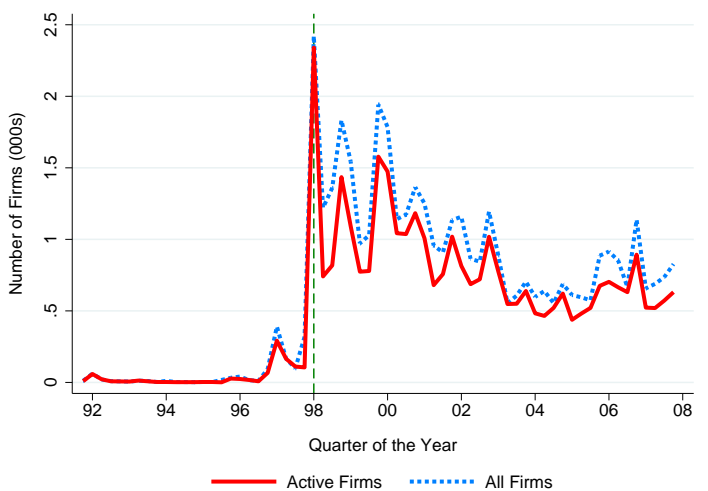

F: Service Providers

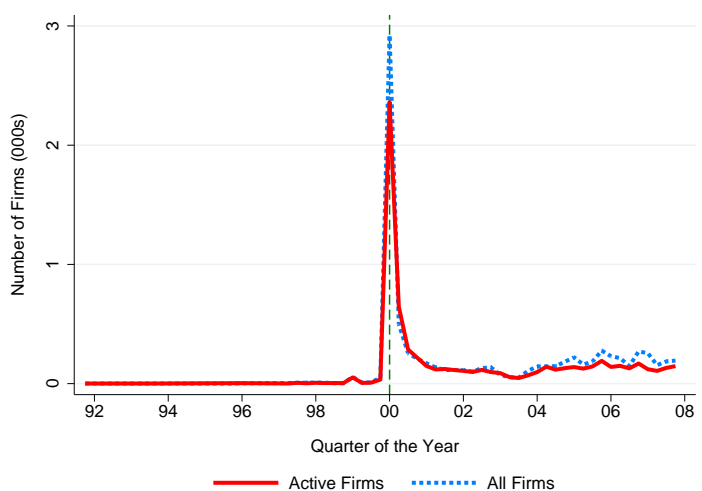

Notes: The figure illustrates the introduction and growth of VAT in Pakistan by tracking the entry of new firms into the tax net between 1992 and 2008. It plots the number of firms who file their first VAT return in the quarter indicated on the horizontal axis. Year $t$ on the horizontal axis denotes the beginning of the financial year and therefore indicates the July-September quarter. Active firm is defined as a firm who reports nonzero activity in at least one of the cells in the return. The difference between All Firms and Active Firms represents "Nil Filers"-the inactive firms who report zero in all cells of the return. Vertical dashed line in each panel demarcate the exact time from which supplies of the production stage became subject to VAT. Please see Appendix A.1 for the classification of firms into manufacturers and other categories. 


\section{Figure IV: Development of VAT in Pakistan - Volume of Transactions}

A: All Firms

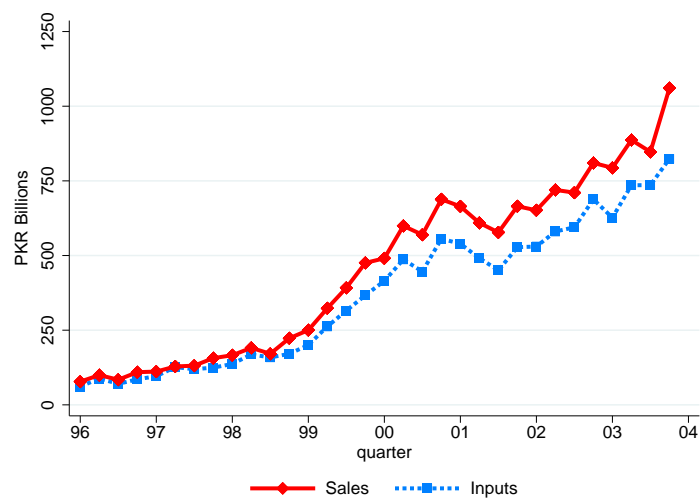

C: Importers

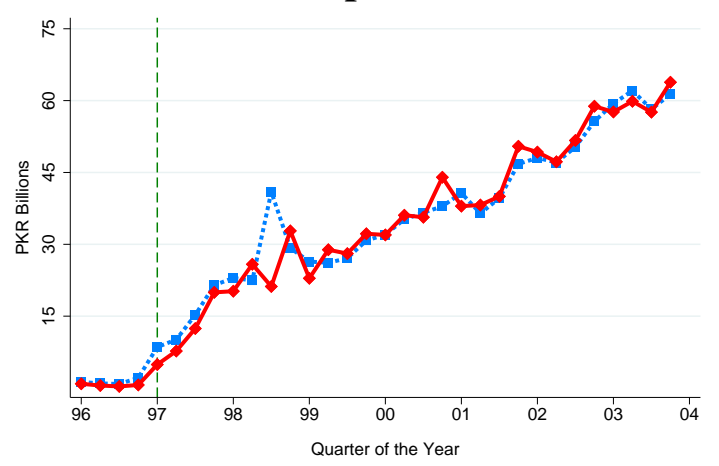

$\longrightarrow$ Sales .......... Inputs

E: Energy Sector

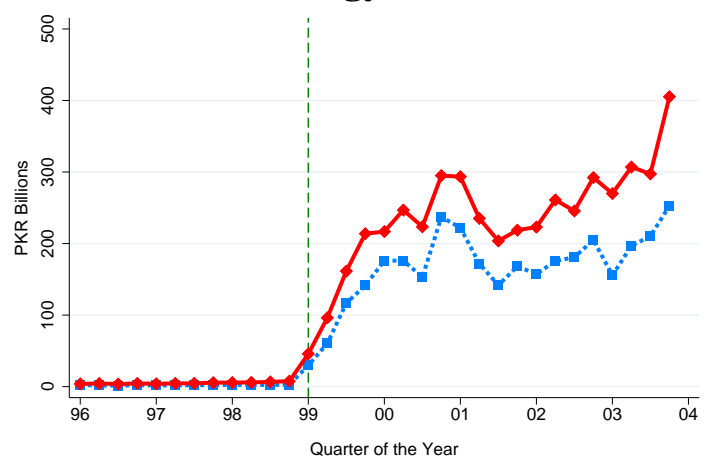

$\longrightarrow$ Sales $\ldots . . . . .$. Inputs
B: Manufacturers

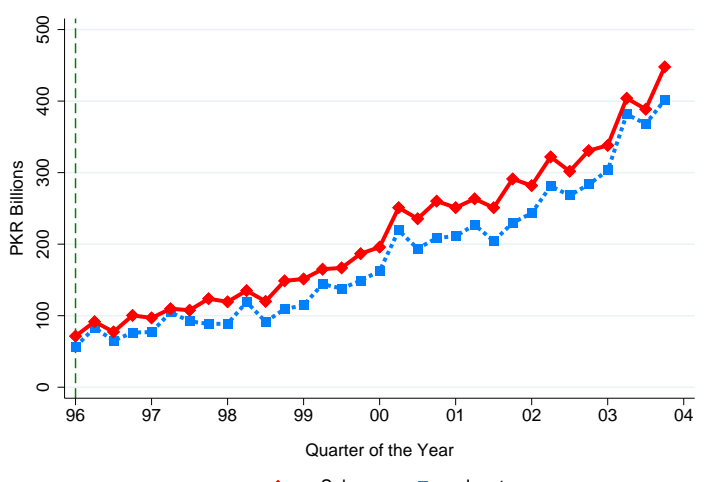

D: Distributors, Wholesalers \& Retailers

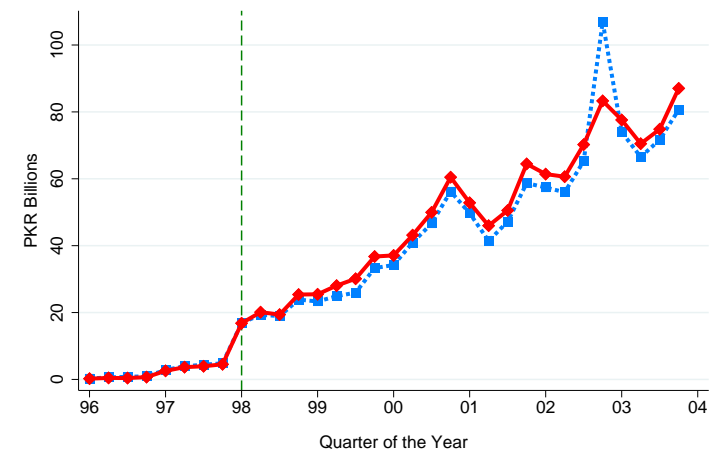

$\longrightarrow$ Sales $\ldots . . . . . .$. Inputs

F: Service Providers

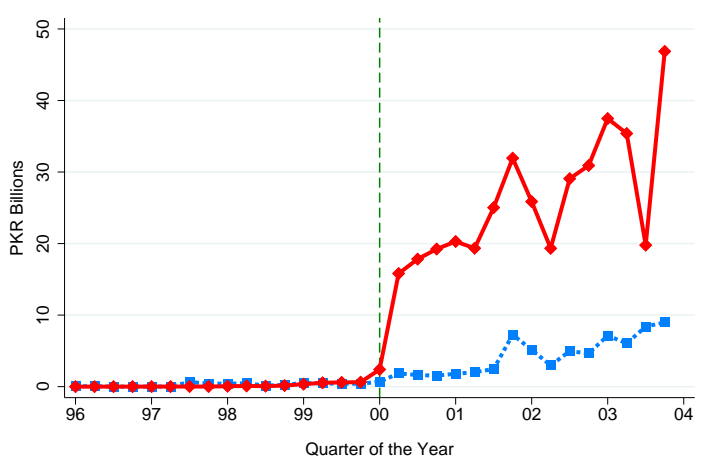

$\longrightarrow$ Sales $\ldots . . . . . .$. Inputs

Notes: The figure illustrates the introduction and growth of VAT in Pakistan by tracking the volume of transactions covered by the tax between 1992 and 2008. It plots the aggregate value of taxable sales and taxable input costs reported by firms in the quarter indicated on the horizontal axis. Year $t$ on the horizontal axis denotes the beginning of the financial year and therefore indicates the July-September quarter. Vertical dashed line in each panel demarcate the exact time from which supplies of the production stage became subject to VAT. Please see Appendix A.1 for the classification of firms into manufacturers and other categories. 

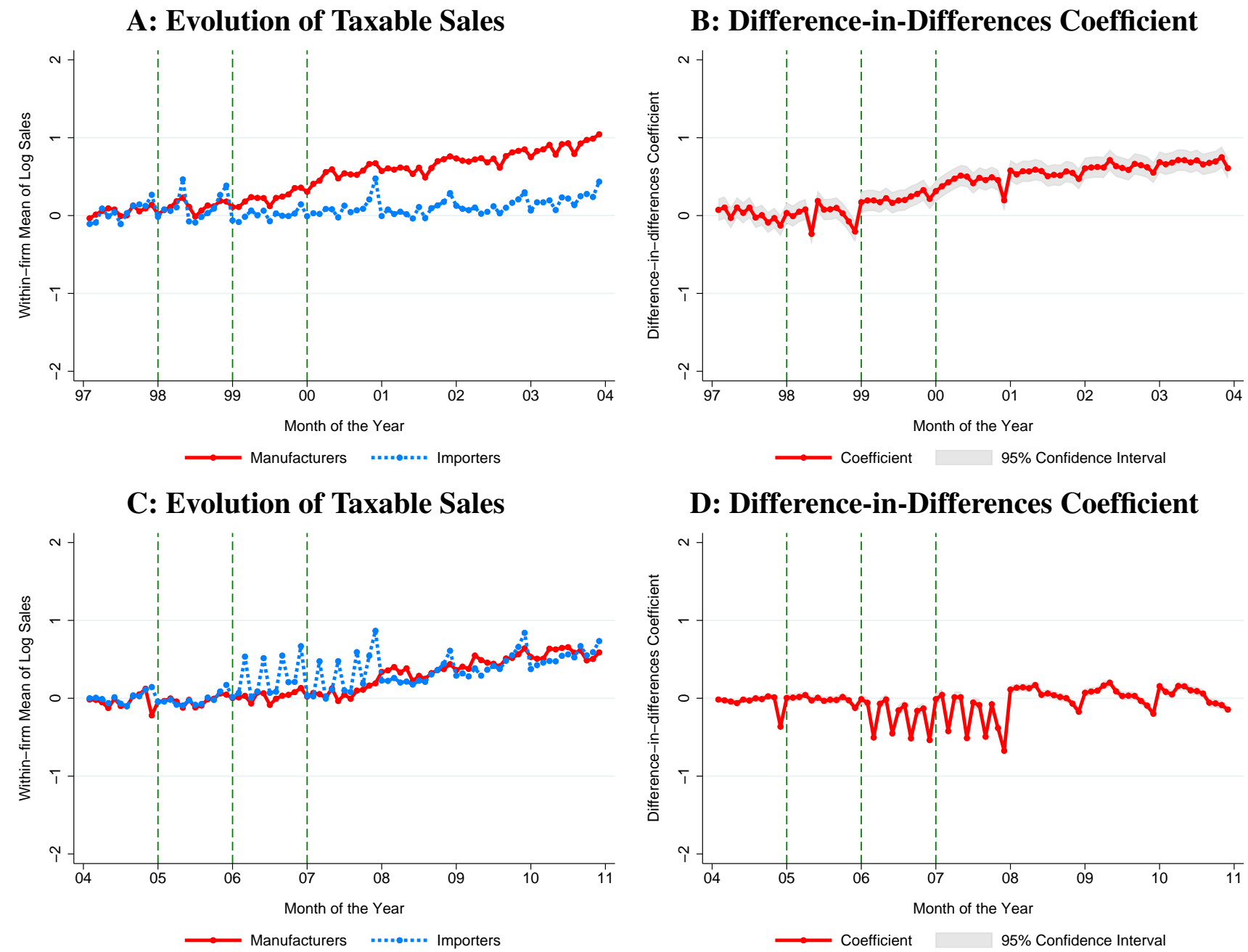

Notes: The figure compares the evolution of taxable sales reported by manufacturers and importers between July 1997 and June 2010. To construct the LHS panels, I regress the log of taxable sales on the full set of firm and month fixed effects, dropping the dummy for July 1997 in Panel A and July 2004 in Panel B. I plot the coefficients on the time dummies of these regressions, run separately for the two groups of firms. The marker for each period, accordingly, approximates the average within-firm sales growth relative to the baseline month for the corresponding group of firms. Year $t$ on the horizontal axis indicates the month July of the year. The RHS panels are the differencein-differences analogues of the LHS panels. Vertical dashed lines in the top two plots demarcate three important event during the period: the extension of VAT to distributor, wholesalers and retailers (1998); energy sector (1999); and services (2000). The last event is almost contemporaneous with the enforcement survey, which was announced by the end of May 2000. 


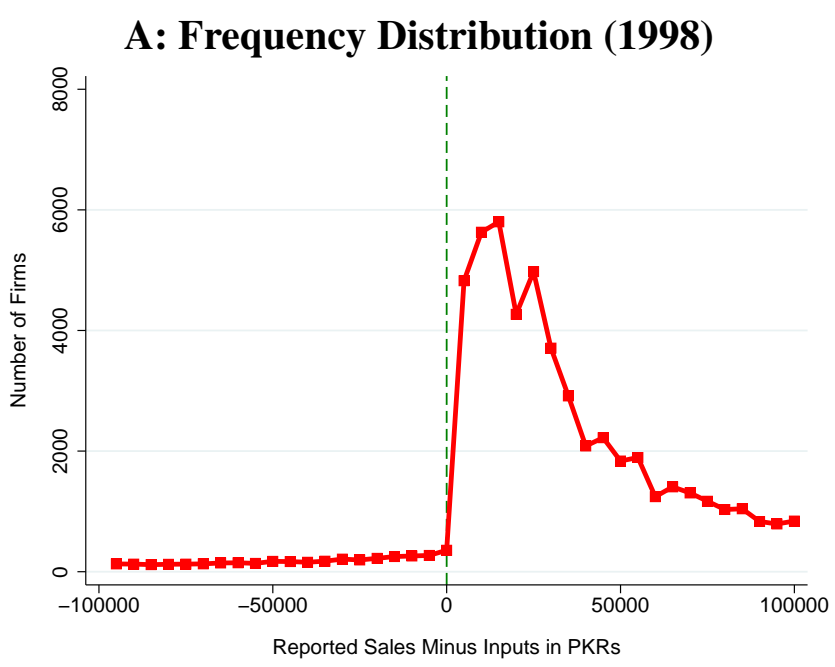

C: Frequency Distribution (1998 Vs. 1999)

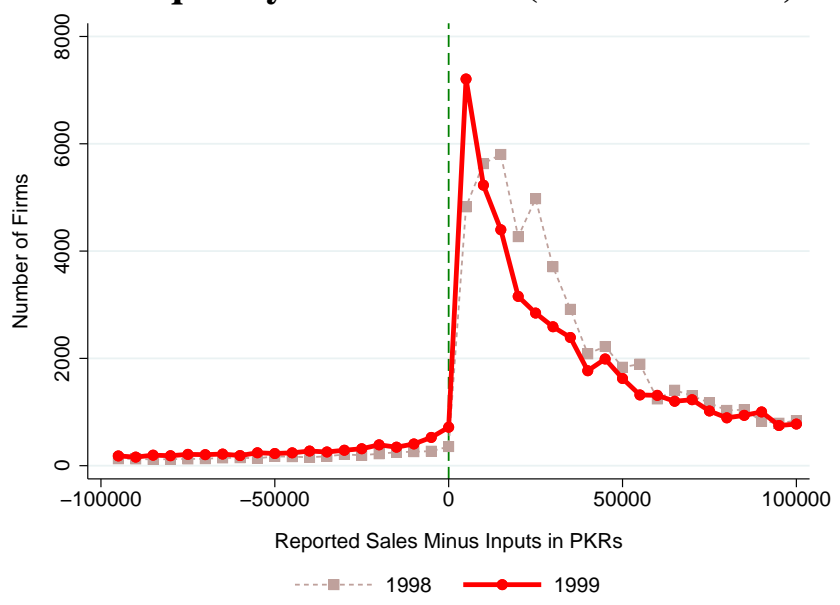

B: Frequency Distribution (1999)

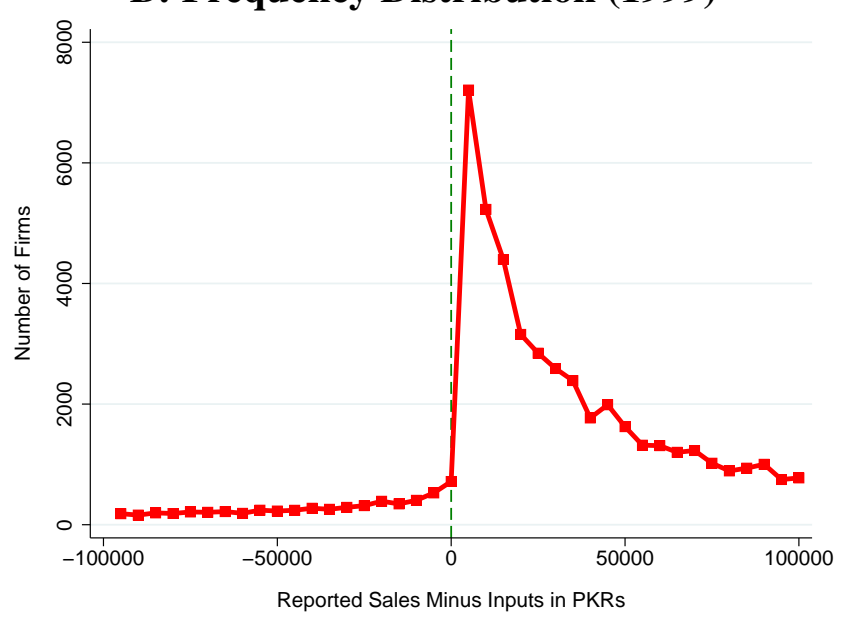

D: CDF (1998 Vs. 1999)

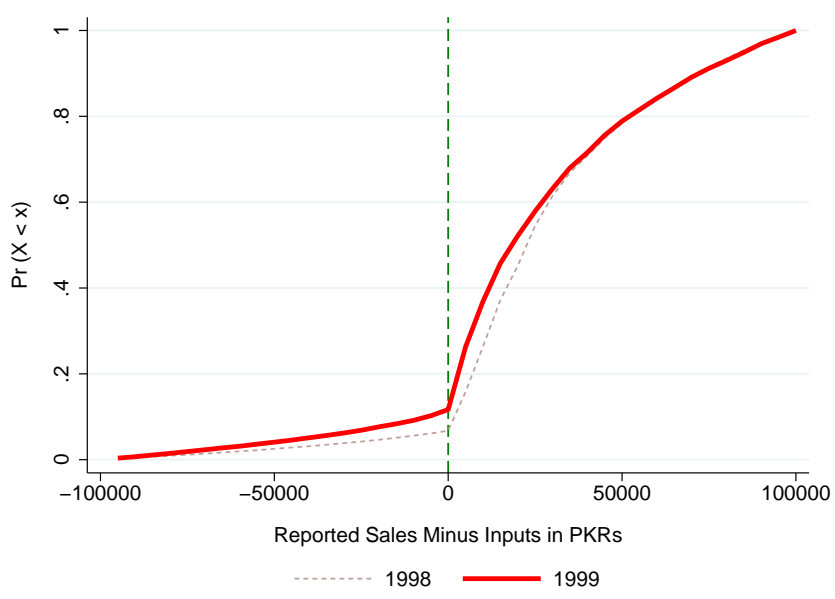

Notes: The figure explores if the discontinuity in evasion costs at the zero-liability point induces firms to bunch towards the right of the point. Panel A-C plot the distribution of $\hat{s}_{i}-c_{i}$ in bins of 5,000 rupees. Vertical dashed line denote the point where reported taxable sales equal reported taxable input costs and the tax liability becomes zero. The tax liability is negative to the left of this point. Panels A and B show the distribution for 1998 and 1999, the years immediately before and after energy inputs such as electricity and gas were made taxable. Panel C compares the two distributions, displaying the leftwards shift of the 1999 distribution. Panel D shows the leftwards shift formally. It plots the corresponding Cumulative Distribution Functions, illustrating that the 1999 distribution is stochastically (first-order) dominated by the 1998 distribution at all points. 


\section{Figure ViI: Participation Response}

\section{A: Registration}

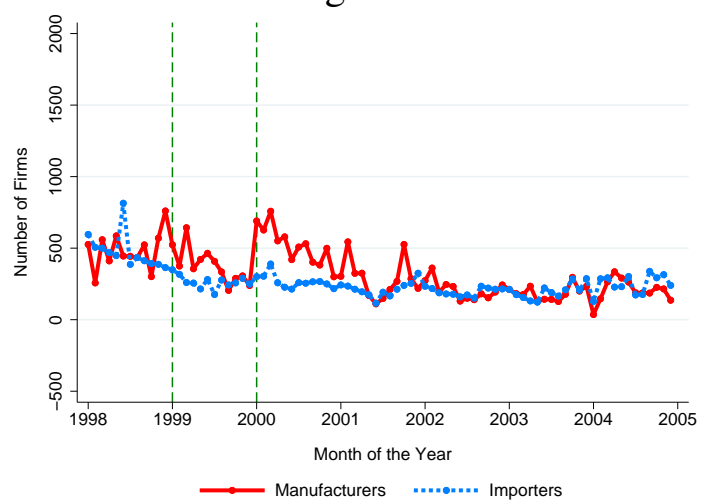

C: Entry

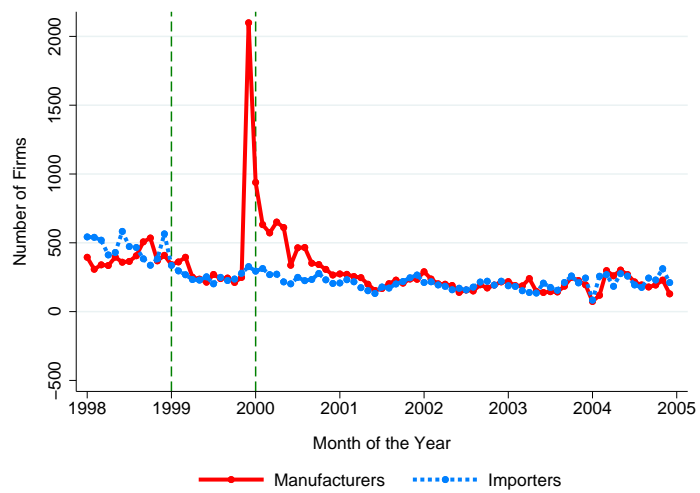

E: Real Entry

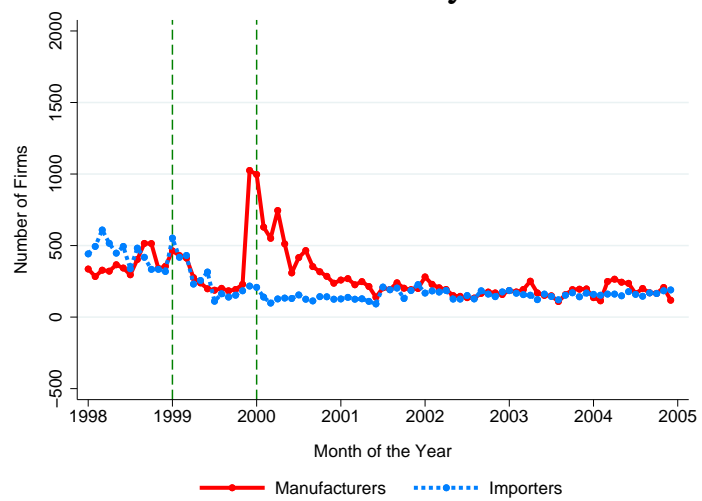

B: Difference-in-Differences

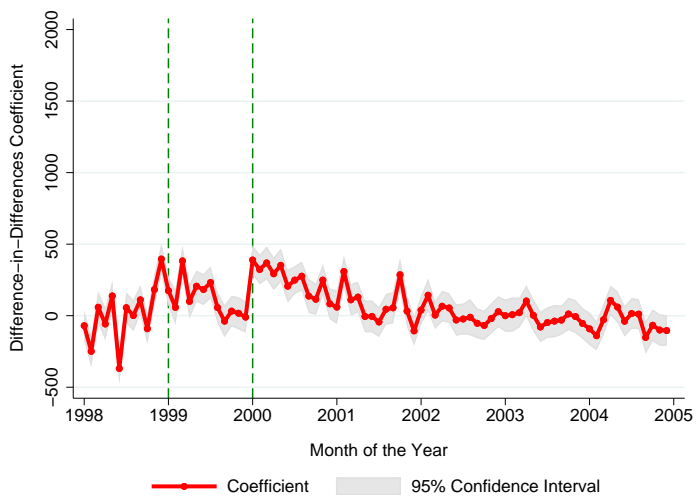

D: Difference-in-Differences

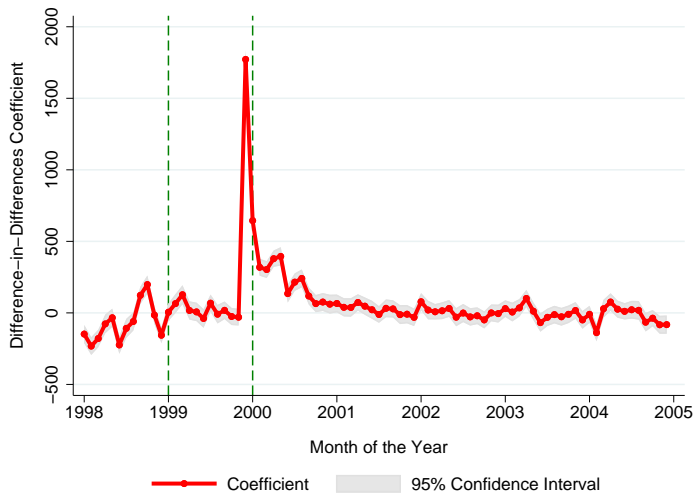

F: Difference-in-Differences

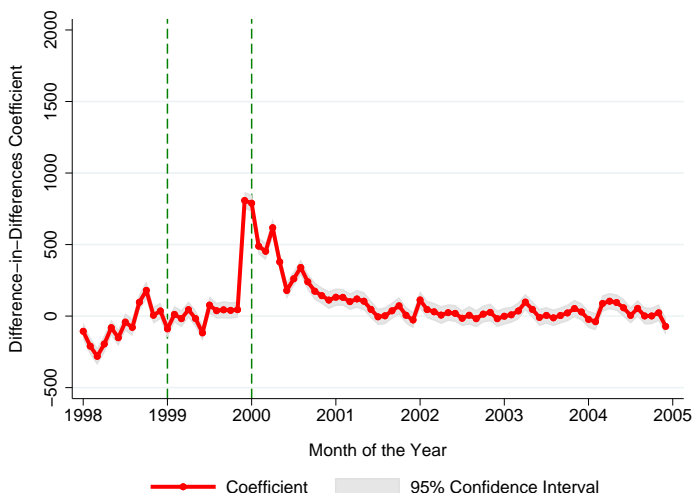

Notes: The figure explores the role of withholding in the extensive margin compliance choices of firms. The LHS panels show the numbers of firms who register (Panel A), file their first return (Panel B), and file their first positiveactivity return (Panel C) in the month indicated on the horizontal axis. The RHS panels plot the corresponding difference-in-differences version of the two series. Year $t$ on the horizontal axis indicates the month July of the year. The vertical dashed lines demarcate the start of the financial years 1999 and 2000. VAT was extended to the energy sector in 1999 and to the services sector in 2000; the tax survey was announced on May 24, 2000. 
TABLE I: FORWARD AND BACKWARD LINKAGES

\begin{tabular}{|c|c|c|c|c|c|c|}
\hline & \multicolumn{3}{|c|}{ Manufacturers } & \multicolumn{3}{|c|}{ Importers } \\
\hline & 2008 & 2009 & 2010 & 2008 & 2009 & 2010 \\
\hline & $(1)$ & $(2)$ & $(3)$ & $(4)$ & $(5)$ & $(6)$ \\
\hline \multicolumn{7}{|l|}{ A: Forward Linkages } \\
\hline Manufacturer & 54.0 & 55.4 & 54.9 & 54.3 & 57.4 & 60.8 \\
\hline Importer & 4.1 & 4.1 & 4.5 & 15.1 & 16.5 & 14.0 \\
\hline Exporter & 2.1 & 0.8 & 0.6 & 2.4 & 1.5 & 1.3 \\
\hline Distributor, Wholesaler, and Retailer & 31.8 & 32.5 & 30.7 & 16.8 & 16.7 & 14.7 \\
\hline Energy & 5.2 & 4.5 & 6.3 & 2.0 & 1.5 & 1.5 \\
\hline Services & 2.7 & 2.5 & 2.8 & 9.2 & 6.3 & 7.4 \\
\hline \multicolumn{7}{|l|}{ B: Backward Linkages } \\
\hline Manufacturer & 45.7 & 45.7 & 44.5 & 11.5 & 11.5 & 15.4 \\
\hline Importer & 10.4 & 12.3 & 11.8 & 11.7 & 11.7 & 9.7 \\
\hline Exporter & 0.4 & 0.6 & 0.7 & 1.2 & 1.0 & 0.9 \\
\hline Distributor, Wholesaler, and Retailer & 7.8 & 7.6 & 9.1 & 8.0 & 8.6 & 5.6 \\
\hline Energy & 14.3 & 11.9 & 11.6 & 0.9 & 0.6 & 1.5 \\
\hline Services & 2.1 & 2.4 & 2.7 & 1.0 & 0.8 & 1.1 \\
\hline
\end{tabular}

Notes: Using transaction level data, I explore forward and backward linkages across firms in various production stages. Columns (1)-(3) shows the percentage of sales made to production stage $j$ in the year indicated in the row heading for manufacturers. Columns (4)-(6) list the corresponding percentages for importers. Panel B replicate the exercise for purchases. Around $66 \%$ of purchases of importers and $18 \%$ of manufacturers are from foreign sellers. Here I show domestic purchases only. 
Table II: TaXable Sales Response

\begin{tabular}{|c|c|c|c|c|c|c|}
\hline & \multicolumn{2}{|c|}{ All Firms } & \multicolumn{2}{|c|}{ Balanced Panel 1} & \multicolumn{2}{|c|}{ Balanced Panel 2} \\
\hline & (1) & (2) & (3) & (4) & $(5)$ & (6) \\
\hline \multicolumn{7}{|l|}{ A: 1997-2003 } \\
\hline \multirow[t]{2}{*}{ Manuf $\times$ Post } & 0.481 & 0.498 & 0.440 & 0.438 & 0.434 & 0.416 \\
\hline & $(0.023)$ & $(0.030)$ & $(0.023)$ & $(0.037)$ & $(0.045)$ & $(0.060)$ \\
\hline \multirow[t]{2}{*}{ Manuf $\times 1998$} & & 0.024 & & -0.004 & & -0.035 \\
\hline & & $(0.028)$ & & $(0.036)$ & & $(0.047)$ \\
\hline Observations & $1,288,552$ & $1,288,552$ & 429,510 & 429,510 & 153,873 & 153,873 \\
\hline \multicolumn{7}{|l|}{ B: $2004-2010$} \\
\hline \multirow[t]{2}{*}{ Manuf $\times$ Post } & 0.013 & & 0.029 & & 0.037 & \\
\hline & $(0.051)$ & & $(0.051)$ & & $(0.043)$ & \\
\hline Observations & $1,292,970$ & & 742,846 & & 200,414 & \\
\hline
\end{tabular}

Notes: The table report the results from the difference-in-differences model (4). The standard errors are in parenthesis, which have been clustered at the industry level. The sample includes both manufacturers and importers. Balanced Panel 1 sample in columns (3)-(4) contains only the firms who file their VAT return at least once in every quarter included in the sample period. In distinction, the Balanced Panel 2 sample includes a firm only if it files its VAT return every tax period included in the sample. The results in Panel B are from a placebo specification exactly similar to one in Panel A but estimated on the 2004-2010 period. The Post dummy indicates a tax period (month) after June 1999 in Panel A and June 2006 in Panel B. 
Table III: Taxable Sales Response OVer Time

\begin{tabular}{|c|c|c|c|c|c|c|c|}
\hline Year $\leq$ & $\begin{array}{c}1999 \\
(1)\end{array}$ & $\begin{array}{c}2000 \\
(2)\end{array}$ & $\begin{array}{c}2001 \\
\text { (3) }\end{array}$ & $\begin{array}{c}2002 \\
\text { (4) }\end{array}$ & $\begin{array}{c}2003 \\
(5)\end{array}$ & $\begin{array}{c}2004 \\
(6)\end{array}$ & $\begin{array}{c}2005 \\
(7)\end{array}$ \\
\hline \multirow[t]{2}{*}{ Manuf $\times$ Post } & 0.249 & 0.233 & 0.332 & 0.395 & 0.450 & 0.489 & 0.490 \\
\hline & $(0.017)$ & 0.017 & 0.020 & 0.022 & 0.022 & 0.023 & 0.027 \\
\hline \multirow[t]{2}{*}{ Manuf $\times 2000$} & & 0.206 & & & & & \\
\hline & & $(0.026)$ & & & & & \\
\hline \multirow[t]{2}{*}{ Manuf $\times 2001$} & & & 0.198 & & & & \\
\hline & & & $(0.028)$ & & & & \\
\hline \multirow[t]{2}{*}{ Manuf $\times 2002$} & & & & 0.195 & & & \\
\hline & & & & $(0.023)$ & & & \\
\hline \multirow[t]{2}{*}{ Manuf $\times 2003$} & & & & & 0.190 & & \\
\hline & & & & & $(0.034)$ & & \\
\hline \multirow[t]{2}{*}{ Manuf $\times 2004$} & & & & & & 0.008 & \\
\hline & & & & & & $(0.049)$ & \\
\hline \multirow[t]{2}{*}{ Manuf $\times 2005$} & & & & & & & 0.030 \\
\hline & & & & & & & (0.099) \\
\hline Observations & 360,669 & 569,495 & 799,627 & $1,042,084$ & $1,288,552$ & $1,516,133$ & $1,673,981$ \\
\hline
\end{tabular}

Notes: The table investigates the dynamics of the taxable sales response. I partition the Manuf $\times$ Post dummy in model (4) into two dummies: Manuf $\times$ Post and Manuf $\times$ Year. I estimate the model on the complete panel sample, restricting it to the period 1997-Year, where Year is the financial year indicated in the title of the column. The Manuf $\times$ Year dummy captures the additional sales response in the given financial year. The standard errors are in parenthesis, which have been clustered at the industry level. The sample includes both manufacturers and importers. The Post dummy indicates a tax period (month) after June 1999. 
Table IV: Participation Response

\begin{tabular}{|c|c|c|c|c|c|c|c|c|c|}
\hline \multirow{2}{*}{$\begin{array}{l}\text { Year } \\
\text { (1) }\end{array}$} & \multicolumn{3}{|c|}{ Registration } & \multicolumn{3}{|c|}{ Entry } & \multicolumn{3}{|c|}{ Real Entry } \\
\hline & $\begin{array}{c}\text { \# Obs. } \\
\text { (2) }\end{array}$ & $\begin{array}{l}\text { \# Counter. } \\
\text { (3) }\end{array}$ & $\begin{array}{c}\% \text { Difference } \\
\text { (4) }\end{array}$ & $\begin{array}{c}\text { \# Obs. } \\
\text { (5) }\end{array}$ & $\begin{array}{c}\text { \# Counter. } \\
(6)\end{array}$ & $\begin{array}{c}\% \text { Difference } \\
\text { (7) }\end{array}$ & $\begin{array}{c}\text { \# Obs. } \\
\quad(8)\end{array}$ & $\begin{array}{l}\text { \# Counter. } \\
\text { (9) }\end{array}$ & $\begin{array}{c}\% \text { Difference } \\
(10)\end{array}$ \\
\hline \multirow[t]{2}{*}{1999} & 5,349 & 3,382 & 0.582 & 3,541 & 3,478 & 0.018 & 3,489 & 3,417 & 0.021 \\
\hline & & & $(0.061)$ & & & $(0.030)$ & & & $(0.032)$ \\
\hline \multirow[t]{2}{*}{2000} & 5,993 & 3,277 & 0.829 & 7,714 & 3,157 & 1.443 & 6,549 & 1,772 & 2.696 \\
\hline & & & $(0.061)$ & & & $(0.035)$ & & & $(0.061)$ \\
\hline \multirow[t]{2}{*}{2001} & 3,728 & 2,454 & 0.519 & 2,780 & 2,321 & 0.198 & 2,717 & 1,725 & 0.575 \\
\hline & & & $(0.077)$ & & & $(0.048)$ & & & $(0.059)$ \\
\hline \multirow[t]{2}{*}{2002} & 2,563 & 2,516 & 0.019 & 2,404 & 2,420 & -0.007 & 2,207 & 1,994 & 0.107 \\
\hline & & & $(0.081)$ & & & $(0.044)$ & & & $(0.054)$ \\
\hline \multirow[t]{2}{*}{2003} & 2,252 & 2,294 & -0.018 & 2,251 & 2,220 & 0.014 & 2,059 & 1,853 & 0.111 \\
\hline & & & $(0.083)$ & & & $(0.048)$ & & & $(0.056)$ \\
\hline \multirow[t]{2}{*}{2004} & 2,556 & 2,941 & -0.131 & 2,525 & 2,625 & -0.038 & 2,337 & 1,908 & 0.225 \\
\hline & & & $(0.070)$ & & & $(0.041)$ & & & $(0.052)$ \\
\hline
\end{tabular}

Notes: The table explores the role of withholding in the extensive margin compliance choices of firms. Column (2) reports the number of manufacturing firms who register in the financial year indicated in the first column. Column (3) reports the corresponding numbers for importers, whom I take as the counterfactual for manufacturers (see Figure VII). The difference between the two numbers as a percentage of the counterfactual is reported in Column (3). I calculate the standard error on the difference using a nonparametric bootstrap procedure. I first create a vector of errors as the difference between the monthly registration of manufacturers and importers. I then create a bootstrapped registration series for manufacturers by adding scrambled errors to the registration series of importers. Finally, I calculate the difference between the bootstrapped and counterfactual series for each financial year. The standard error is the average percentage difference between the two series. I draw 100 bootstrapped series for this purpose. Columns (4)-(10) are created analogously, only difference being that I investigate the outcomes entry and real entry in place of registration. Entry here is defined as the month a firm files its first return in and real entry as the month the firm files its first positive-activity return in. 